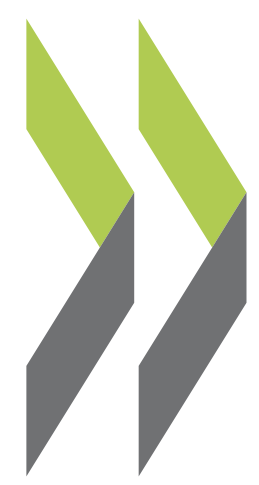

OECD Economics Department Working Papers No. 290

\title{
Encouraging \\ Environmentally Sustainable \\ Growth in Canada
}

Ann Vourc'h 


\section{ECONOMICS DEPARTMENT}

by

Ann Vourc'h

Most Economics Department Working Papers beginning with No. 144 are now available through OECD's Internet Web site at http://www.oecd.org/eco/eco/ 


\begin{abstract}
RÉSUMÉ
This paper analyses aspects of natural resource policy and environmental policy in Canada. In the taxation of resource-based activities, the management of water supply and the Atlantic fisheries management, the paper finds that there are incentives that may lead to overexploitation, over-harvesting or over-use, with possible harmful environmental consequences. Water prices are kept low, especially for agricultural use, exacerbating water availability problems in some areas, whereas the ban on bulk water removal and exports reveals a high implicit valuation of water. The use of economic water pricing and transferable water rights in some areas would establish more consistent incentives. The evolution of the crisis in the Atlantic fisheries illustrated the problems of balancing short-term adjustment costs against long-term sustainability. A more precautionary approach in setting total allowable catches and the removal of incentives for labour to remain in the sector may be needed. Canada also faces a number of challenges for environmental policy, in particular to deal with toxic substances, air pollution and climate change mitigation. Objectives and intermediate targets may be better defined, and some institutional features may have reinforced the usual difficulty faced by environmental policy of imposing costs on particular sectors in order to provide diffuse benefits to the public. The frequent recourse to voluntary agreements has not proved effective in dealing with toxic substances or greenhouse gas emissions. A greater use of economic instruments would improve the cost-effectiveness of environmental policy.
\end{abstract}

JEL Classification: H23, Q00, Q20, Q28, Q40, Q48

Keywords: Canada, sustainable development, environmental policy.

$* * * * *$

Ce document analyse certains aspects de la politique des ressources naturelles et de l'environnement au Canada. Considérant le traitement fiscal des activités fondées sur les ressources, la gestion de l'approvisionnement en eau et des pêcheries de l'Atlantique, le document trouve que certaines incitations en place peuvent encourager une surexploitation, un prélèvement excessif ou une surconsommation, avec des conséquences dommageables possibles pour l'environnement. Le prix de l'eau est maintenu très bas, en particulier pour l'agriculture, ce qui exacerbe les problèmes d'approvisionnement dans certaines régions, alors que l'interdiction des prélèvements et exportations massifs révèle une haute valorisation implicite de l'eau. Une tarification plus économique et des droits sur l'eau négociables établiraient des incitations plus cohérentes. L'évolution de la crise des pêcheries de l'Atlantique illustre la difficulté de mettre en balance les coûts d'ajustement à court-terme et la viabilité à long-terme. La fixation du total admissible des captures pourrait respecter plus strictement une approche de précaution, et les incitations pour la population active à rester dans ce secteur pourraient être réformées. Le Canada fait aussi face à certains défis pour la politique de l'environnement, en particulier dans le domaine des substances toxiques, de la pollution de l'air et de l'atténuation du changement climatique. Les objectifs et les cibles intermédiaires pourraient être mieux définis, et certains caractéristiques institutionnelles ont peut-être renforcé la difficulté générale pour la politique de l'environnement d'imposer des coûts à un secteur particulier pour des bénéfices diffus au public. Le recours fréquent aux approches volontaires n'a pas permis de s'attaquer efficacement aux problèmes des substances toxiques et des émissions de gaz à effet de serre. Une plus grande utilisation d'instruments économiques permettrait d'améliorer l'efficacité par rapport aux coûts de la politique de l'environnement.

Classification JEL : H23, Q00, Q20, Q28, Q40, Q48.

Mots clés : Canada, développement durable, politique environnementale.

Copyright: OECD 2001. All rights reserved.

Applications for permission to reproduce or translate all, or part of, this material should be made to: Head of Publications Service, OECD, 2 rue André-Pascal, 75775 PARIS CEDEX 16, France 


\section{TABLE OF CONTENTS}

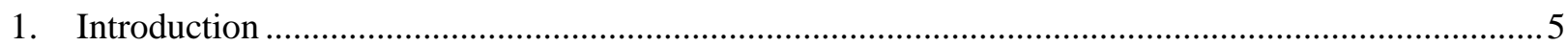

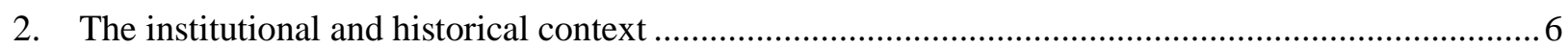

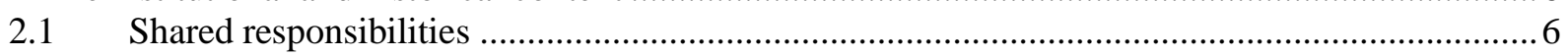

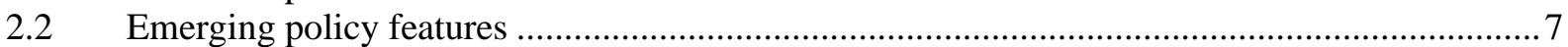

3. Incentives for resource-based activities: the conflict with sustainability ....................................... 7

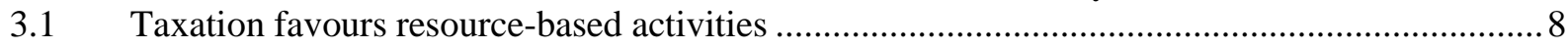

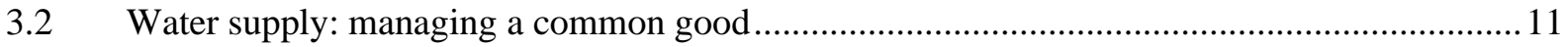

3.3 The Atlantic groundfisheries: an example of conflicting policies..........................................18

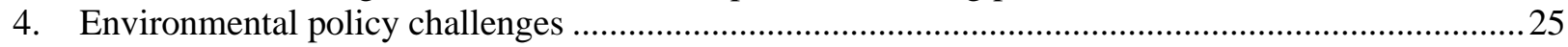

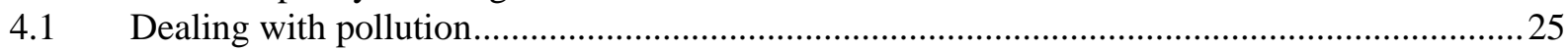

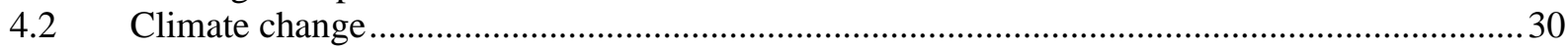

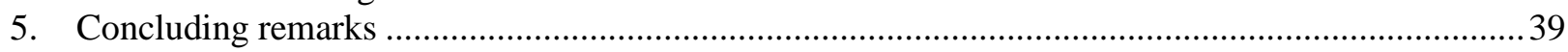

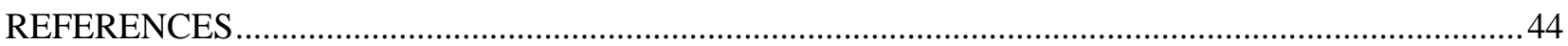

ANNEX I. INSTITUTIONS AND POLICIES IN THE AREA OF RESOURCES

AND THE ENVIRONMENT IN HISTORICAL PERSPECTIVE

ANNEX II. BACKGROUND MATERIAL ON THE MANAGEMENT

OF THE ATLANTIC FISHERY 


\section{Boxes}

1. Improving water allocation through water markets in Alberta ........................ 14

2. The collapse of the Atlantic groundfishery ...................................... 19

3. Voluntary agreements: the international evidence ................................... 27

4. Summary of conclusions and recommendations for reform ........................ 40

\section{Tables}

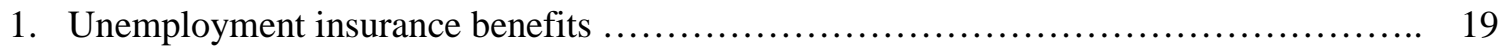

2. Economic costs of implementing the Kyoto Protocol ............................. 32

\section{Figures}

1. Effective marginal tax rates on investment ...................................... 9

2. Average effective tax rates for base-metal operations ............................. 10

3. Water resources in Canada: an international comparison ............................. 12

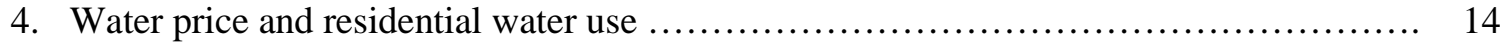

5. Federal government assistance to the Atlantic fishery ............................. 21

6. Government transfers to marine fisheries ............................................ 22

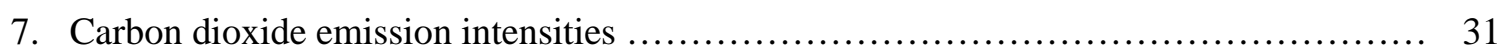

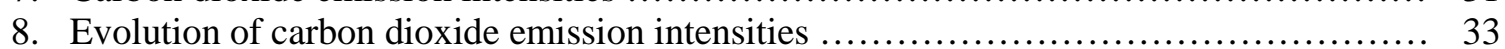

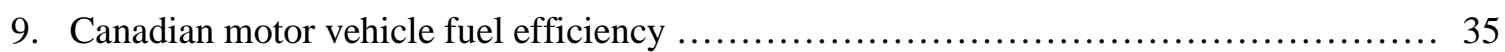

10. Petrol taxes in international comparison ......................................... 36 
ECO/WKP(2001)16

\title{
ENCOURAGING ENVIRONMENTALLY SUSTAINABLE GROWTH IN CANADA ${ }^{1}$
}

\author{
Ann Vourc'h ${ }^{2}$
}

\section{Introduction}

1. Canada accounts for a relatively large share of the planet's natural resources (for example, around 10 per cent of both the world's forests and renewable fresh water supply). The economy still relies considerably on resource-based activities, whose development has been encouraged by government policies. Although, apart from the Atlantic groundfish sector, the limits to the availability of resources have generally not been reached, the sustainability of such policies is an issue in the long run. Resource-based production is generally pollution-intensive and may cause serious problems, notwithstanding the Canadian environment's substantial assimilative capacity in most regions compared with other OECD countries.

2. In the Canadian context, policies to address these issues face a number of specific constraints: the proximity and extensive economic integration with the United States; the enormous inter-provincial differences in environmental conditions and resource availability; the shared jurisdiction between the federal and provincial governments in this area; and the need to honour commitments to Aboriginal management of resources.

3. In an effort to strengthen the federal government's performance in protecting the environment and bring consistency to its policies, legislation was enacted in 1995 that requires departments to table sustainable development strategies in 1997 and subsequently every three years - comprising objectives and action plans to achieve them - under the auspices of a Guide to Green Government. This guideline document directs that environmental interests be included with social and economic concerns for more balanced decision-making in all sectors. Recently, the government has committed itself to place greater emphasis on sustainable development in policy decisions.

4. Rather than looking at sustainable development in its broadest definition-including the environment, economic and social pillars - this paper examines how to make growth more environmentally sustainable, and places less emphasis on social aspects. After a presentation of the institutional and policy setting, a limited number of important natural resource and environmental issues are reviewed, ${ }^{3}$ looking at

1. This paper was originally produced for the OECD Economic Survey of Canada, which was published in August 2000 under the authority of the Economic Development Review Committee. Working papers on the same subject have been published for Norway, Finland, Germany, the United States, Denmark and Sweden, and are forthcoming for a number of other countries

2. Ann Vourc'h is an economist in the Economics Department of the OECD. The author would like to thank Paul O’Brien, Jean Cinq-Mars, Peter Jarrett, Tom Jones and Hannes Suppanz for ideas, comments or advice and Anick Lotrous, Lillie Kee and Veronica Humi for their technical support.

3. Although forestry is an important activity in a number of Canadian provinces, and there are periodic public debates about the sustainability of this activity, this section does not review forest policy. At the national level, the annual growth in wood stock is larger than the annual harvest (OECD, 1998), so that in quantitative terms the intensity of forest resource use seems sustainable. There are important and more 
how they are being tackled, and in particular at how well natural resource, environmental and sectoral/economic policies are integrated so as to take account of spillovers between them. Some of the apparent policy problems are then outlined, including the integration of policies, the choice of instruments and institutional aspects of policy implementation.

\section{The institutional and historical context ${ }^{4}$}

\subsection{Shared responsibilities}

5. Canada is a federal state in which each of the ten provinces and three territories has considerable jurisdictional power, much more than states in the United States, for example. As the environment is not explicitly addressed in the Constitution, the division of powers regarding environmental policy between the various levels of government flows to a great extent from jurisdiction over resources. Natural resources fall largely within the provincial domain, and they have the authority to legislate with respect to both publicly and privately owned resources within their territory. However, the federal government also has responsibility over some resources transcending provincial boundaries, in particular fish, as well as through its sectoral power over agriculture and navigation, and through more general constitutional provisions (see Annex I). In addition, the federal government is in charge of the environmental assessment of projects for which it has decision-making authority, for example as a proponent, land manager, source of funding or regulator.

6. Hence, for many resource and environmental areas and issues, responsibility is shared between the federal and provincial governments, implying that the two levels of government have to co-operate to act effectively. Co-operation between the federal government and the provinces is necessary when negotiating, and signing international agreements over natural resources or the environment. Foreign affairs are the exclusive responsibility of the federal government, but treaty obligations within areas of provincial competence require implementation by the provinces. Environmental issues where responsibility is shared include climate change, transborder (vis-à-vis the United States) environmental problems (such as acid rain, an issue in the eastern provinces), biodiversity, ${ }^{5}$ toxic substances (due to the health dimension), pollution of navigable waters and fresh-water fisheries.

7. The shared nature of environmental jurisdiction is at the root of the "stakeholder" approach often used in the country. The Canadian Council of Ministers of the Environment (CCME), composed of the environment ministers of the ten provinces, the three territories and the federal government, is the main forum through which federal/provincial co-ordination on environmental matters, both national and international, is negotiated and formalised. In addition, various types of bilateral agreements for environmental management have been signed between the federal government and individual provinces (see Annex I). Federal-provincial-territorial ministerial councils have also been established for natural resource issues, such as forests, agriculture, wildlife, minerals and metals, fisheries and aquaculture, and a joint body for energy and the environment. The stakeholder approach also implies broader consultation with the private sector, individuals and environmental and other interest groups which are affected by decisions.

complex issues at the intersection of economics and the environment associated with forest exploitation, but these go beyond the time and space available for this paper.

4. For example a comprehensive survey of institutions and the governance of sustainable development see OECD $(2000 a)$.

5. The federal government has just introduced a draft bill for protecting species at risk. 
8. Environment departments have responsibility for environmental protection at both levels of government, but substantial powers have been left in the hands of other departments, responsible for agriculture, energy (and more widely natural resources) and transport, but also fisheries and health. As in other OECD countries, this division of responsibilities also reflects the fact that other goals may sometimes override environmental objectives.

9. One interesting institutional feature, unique in the OECD, is the existence of a Commissioner of the Environment and Sustainable Development, created in 1995 to audit federal policies for sustainable development and implementation of other environmental commitments by the federal government. The yearly reports of the Commissioner play an important role in providing and disseminating information, raising public awareness and providing recommendations for policy reform to the departments concerned.

\subsection{Emerging policy features}

10. Initially, provinces focused on encouraging resource development, as royalties were (and still are in some cases) an important source of revenues. For the past several decades, they have also progressively worked towards achieving long-term resource conservation, creating the regulations and institutions for that purpose. The federal government has also played some role in resource development and conservation, through its spending power, as well as with more direct policy intervention (see Annex I).

11. The main mechanisms to regulate pollution were established in the early 1970s, when a number of incidents both within Canada and abroad heightened public concern about environmental problems and brought them onto the policy agenda. Environmental policy activity subsequently slowed but revived in the late 1980s when public concern about environmental issues re-emerged. Important environmental laws were introduced in this period, including the Canadian Environmental Protection Act. In 1990, the federal government also launched the Green Plan, a policy framework and action plan for sustainable development, in which it committed itself to $\mathrm{C} \$ 3$ billion in additional spending on the environment over the following five years. In 1995, it proclaimed the Canadian Environmental Assessment Act. As a result of fiscal consolidation efforts at both levels of government, however, the 1990s were marked by important cuts in the federal and provincial budgets for the environment.

12. Initially based mainly on regulatory standards, environmental policy has increasingly looked to voluntary agreements over the 1990s. The use of economic instruments has been rare at all levels of government, and, even though the issue has raised interest in the past decade, it is not increasing significantly. Litigation has also played a relatively small role, in contrast to the US experience. Cost-benefit analysis has been relatively rarely used as a basis for policy decisions. However, it is becoming more common in policy discussions. For example, at the federal level, Environment Canada has developed models to estimate the environmental benefits of reducing air pollution, and these models are being diffused to provincial and territorial governments, thereby enhancing their capacity to use cost-benefit analysis.

\section{Incentives for resource-based activities: the conflict with sustainability}

13. Various direct and indirect subsidies to resource-based activities or consumption, initially provided to encourage the exploitation of the generous endowment of natural resources, remain in place. This can result in over-exploitation, over-harvesting or over-use. Harmful environmental consequences can also be serious in some cases. 


\subsection{Taxation favours resource-based activities}

14. Historically, resource-based sectors have benefited from preferential tax treatment from the federal and provincial governments. ${ }^{6}$ This has encouraged the development of resource extraction activities, contributed to depressing costs and to some extent (depending on the degree of market competition) prices. The incentives are particularly important in the non-renewable resource sectors, which face especially low effective tax rates on marginal investment; in the oil and gas sector, for example, the rates are a third of those in the manufacturing sector and a quarter of those in most services activities (Figure 1). ${ }^{7}$ Tax incentives provided to investment in the forestry sector are lower than for non-renewable resource sectors, close to the range of those granted to manufacturing when both large and small firms are considered. Grouped with agriculture, the fisheries benefit from the same kind of tax treatment as nonrenewables. As far as energy investments are concerned, the federal income tax treatment given to renewable and non-renewable energy is relatively similar (Report of the Commissioner of the Environment and Sustainable Development, 2000). ${ }^{8}$ Tax incentives to investment are provided mainly through the corporate income tax regime, with taxes affecting the cost of capital, as well as through resource levies such as royalties.

15. By and large - with the exception of Quebec - provincial corporate income tax regimes mirror the federal system. Both levels of government provide preferential tax treatment to mining and oil and gas, through generous write-offs for exploration, development and capital expenses borne by firms in those sectors. ${ }^{9}$ In addition, exploration and development expenses can be associated with a flow-through share issue, a unique provision of the Canadian tax system, which allows a company that has insufficient taxable income to utilise the deductions to transfer them to investors. ${ }^{10}$ Prior to the tax measures announced in the 2000-01 federal budget (see OECD 2000b, Chapter III), no substantial step had been taken to level the playing field for business investment. ${ }^{11}$

6. Incidentally, it could be noted that tax breaks provided by the federal government to resource-based sectors presumably result in increasing the royalties provinces can extract, thereby constituting an implicit transfer to these provinces.

7. These rates take into account all federal and provincial tax provisions related to investment (corporate income taxes, capital taxes and sales tax on business inputs) except for royalties, which are considered as a cost rather than a tax. If royalties paid to provincial governments are treated as a tax, the marginal effective tax rate for the upstream activities of the oil and gas industry is 18.2 per cent, which is close to the average for all industries.

8. The 2000 Report of the Commissioner of the Environment and Sustainable Development confirms the result found in "The Level Playing Field Study", released in 1996 by Natural Resources Canada, which concluded that the variation in tax assistance between renewable and non-renewable energy projects was not large. There are some important exceptions, however, including oil sands and coal mines, nuclear technology, alternative fuels and certain energy efficiency investments.

9. In the federal corporate income tax system, exploration costs can generally be immediately deducted against income at 100 per cent, and development expenditures at a 30 per cent rate on a declining balance basis. Accelerated capital-cost allowances have also been provided.

10. The introduction of flow-through shares resulted in large amounts of financing being raised for mineral exploration in Canada, especially in the late 1980s (Brewer and Lemieux, 1997).

11. On the contrary, provinces introduced new preferential tax provisions for the minerals and metals sector in 1998, for example through increases in prospecting grants and in various tax allowances, and exemption of fuel taxes in the mining process (Natural Resources Canada, 1999). 
Figure 1. Effective marginal tax rates on investment (1) 1997

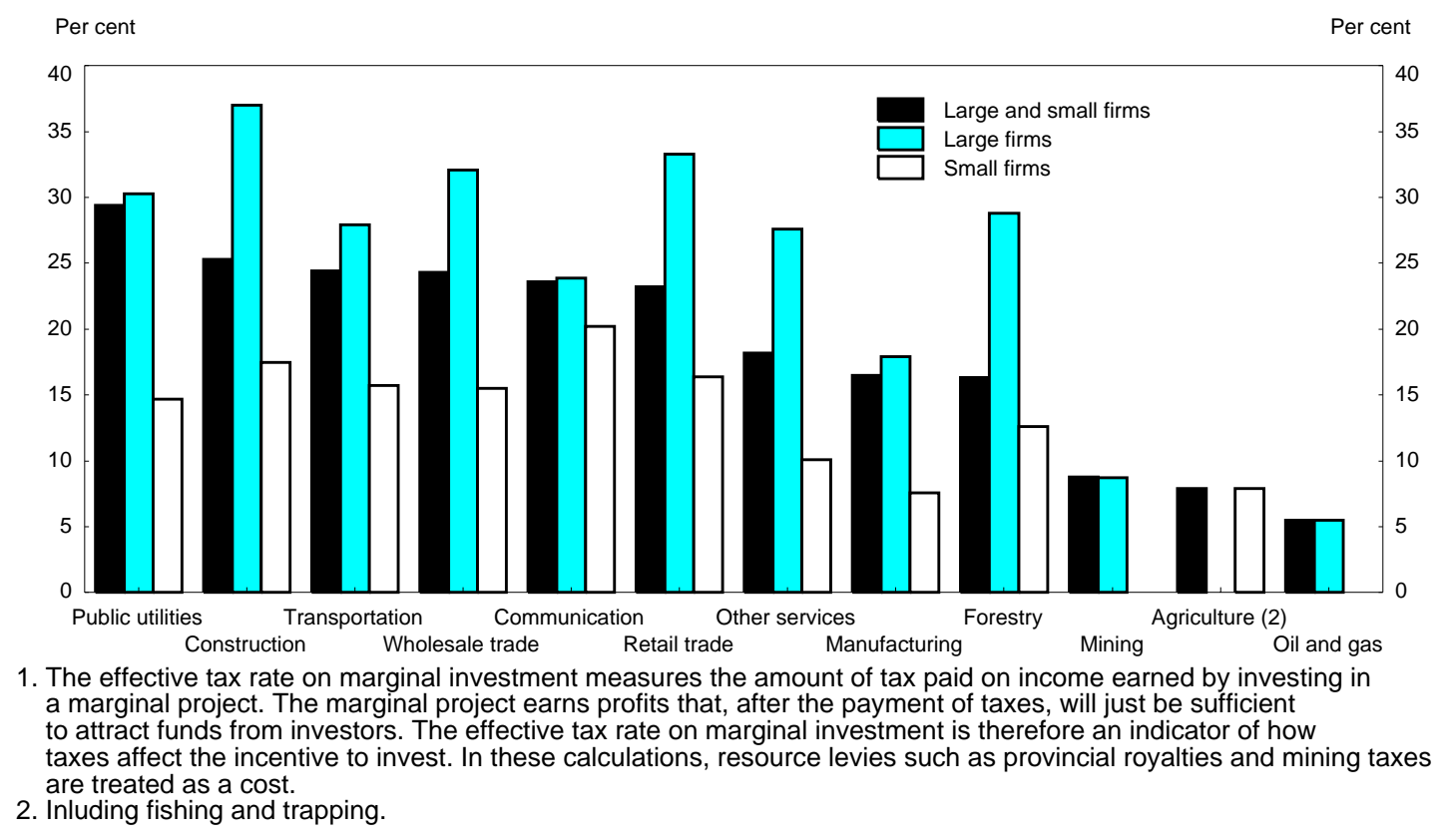

Source: Report of the Technical Committee on Business Taxation (1997).

16. The special treatment is meant to recognise exploration risk and other specific risks unique to the non-renewables sector, and to be comparable with the kind of treatment granted to the same sectors in other countries (Government of Canada, 1996). However, the necessity to mitigate investors' risk by lowering effective tax rates on marginal investment appears questionable. In fact, taxation in itself is a factor attenuating such risk, as losses can be deducted from taxable income, and flow-through share provisions provide a guarantee that the investor will be able to profit from the deductibility of losses. ${ }^{12}$ As for the competitiveness issue, recent calculations by Natural Resources Canada for the mining sector show that average effective tax rates, including corporate income taxes and royalties, are generally below those of other countries or states (Figure 2) (Brewer, 1996).

12. The primary issuer of flow-through shares are those companies that cannot take immediate advantage of the allowable write-offs available through the tax system. Such companies would tend to be small or in a start-up phase, with limited access to other forms of financing. 
Figure 2. Average effective tax rates for base-metal operations (1) 10 per cent internal rate of return

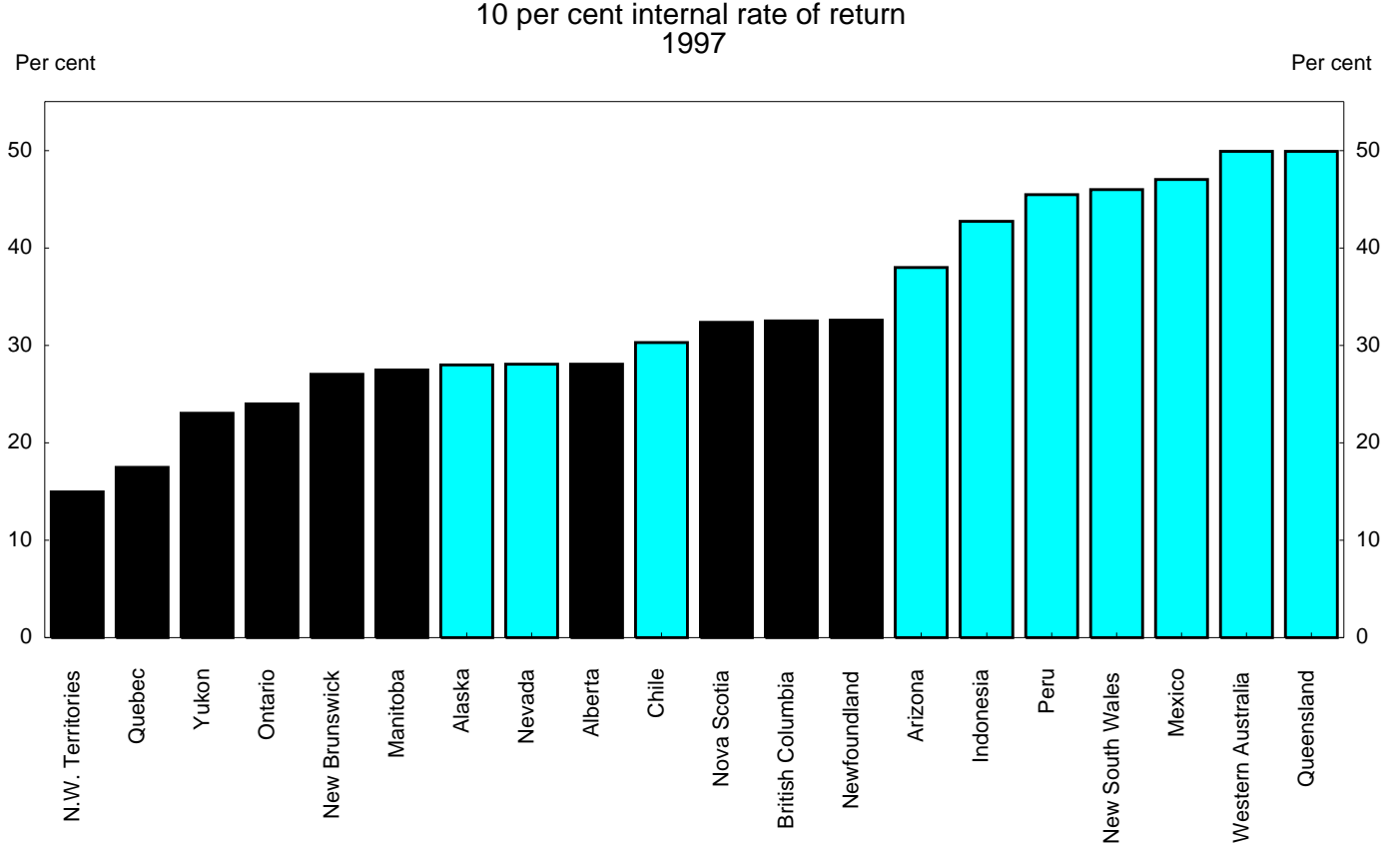

1. Ratio of the net present value of all taxes (including mining taxes and royalties) to the net present value of acounting income, for a project with a $10 \%$ pre-tax internal rate of return, using a $7.5 \%$ discount rate. Source: Technical Committee on Business Taxation, based on data provided by Natural Resources Canada.

17. Resource levies, such as royalties or stumpage fees can also affect investment decisions. In theory, they are meant to tax the rent associated with the exploitation of the resource owned by provincial governments, that is the profit earned in excess of the level required to induce a firm to undertake the investment, and should therefore not affect firms' incentive to invest. In practice, however, it is very difficult to estimate the rent and design a tax system that does not distort production decisions. Resource levies are generally based on output or income and are therefore not neutral. They vary substantially across Canadian provinces, which also earn revenue from the auction of sub-surface exploration rights. ${ }^{13}$ In the oil and gas sector, they have tended to diminish as development shifts from conventional reserves to more costly offshore production or oil sands mining. In the forestry sector, the level of stumpage fees is at the centre of a long-standing trade conflict opposing Canadian provinces, in particular British Columbia, Quebec, Ontario and Alberta, and the United States, the latter accusing the former of subsidising lumber exports through low stumpage fees. This subject is highly controversial and has given rise to many disputes and agreements, with no clear final resolution. While assessing the extent to which provinces subsidise

13. Oil and natural gas sub-surface rights are systematically auctioned in Alberta. In the case of metals and non-metallic minerals, a competitive bidding process is implemented if there are several applications for the rights. 
production by not taxing all the economic rent is a complex task, there is at least one example of resource for which it seems that the economic rent is not at all extracted by governments, namely water.

\subsection{Water supply: managing a common good}

18. Fresh water is generally an extraordinarily abundant natural resource in Canada. ${ }^{14}$ That abundance and the ensuing policies have resulted in relatively heavy water use - water abstraction (withdrawal) ${ }^{15}$ per capita is the second highest in the OECD, although, overall, the intensity of water use remains very low compared with most OECD countries (Figure 3). ${ }^{16}$ Jurisdiction over water resources is shared among the three levels of government. In general, Canadians view water as a special resource requiring particular protection. The exploitation of water is partly inhibited by a reluctance to consider it as a commodity as any other and to allow it to be traded. This reluctance exacerbates water shortages in some areas, ${ }^{17}$ while potential export opportunities may be lost in part for fear that international trading rules would impose economically rational allocation domestically. Canadian governments have prohibited water export also because of concerns that bulk removals of water may have significant ecological effects which at present are uncertain.

\subsubsection{The need for water trading or pricing}

19. The regulatory framework for water withdrawals is based on "use permits" or licenses tied to a specific site and use for an indefinite period of time. ${ }^{18}$ Some provinces require that a fee be paid for these permits, but in most of them, including Alberta and Ontario, licenses are simply granted without charge. ${ }^{19}$ The systems differ when dealing with shortages: in Alberta, the seniority of a license defines its priority to draw all of its maximum allowable volume, while in Ontario, the allocation of water withdrawal is left to a large extent to the discretion of the administrators of the permit system.

14. Fresh water supply is measured as precipitation less losses due to evaporation and out-flows to neighbouring countries or to the sea, plus inflows from neighbouring countries. Canada has about 9 per cent of the world's renewable fresh water, but also 7 per cent of the world's landmass. A large part of that water drains northward, though, and is not available to the Canadian population living near the southern border.

15. Water abstraction is the volume of water taken out from waterways or aquifers.

16. The intensity of use is measured by the ratio of gross abstractions to available freshwater resources.

17 Water is sometimes in short supply during summer and drought periods in southern the southern parts of the Great Lakes basin, where urban needs have come into conflict with rural and agricultural demands.

18. Initially, water rights were riparian, that is vested in the owner of a body of water or neighbouring land. Provinces have reformed this system at various times, as far back as the end of last century in Alberta for example, and only in the early 1960s in Ontario.

19. Renzetti and Dupont (1999) indicate that charges applied to water withdrawal vary from a simple one-time payment when the license is issued (Manitoba) to a rather complex fee schedule depending on the use of water, the location and characteristics of the firm or agency withdrawing the water, and the quantity of water. 

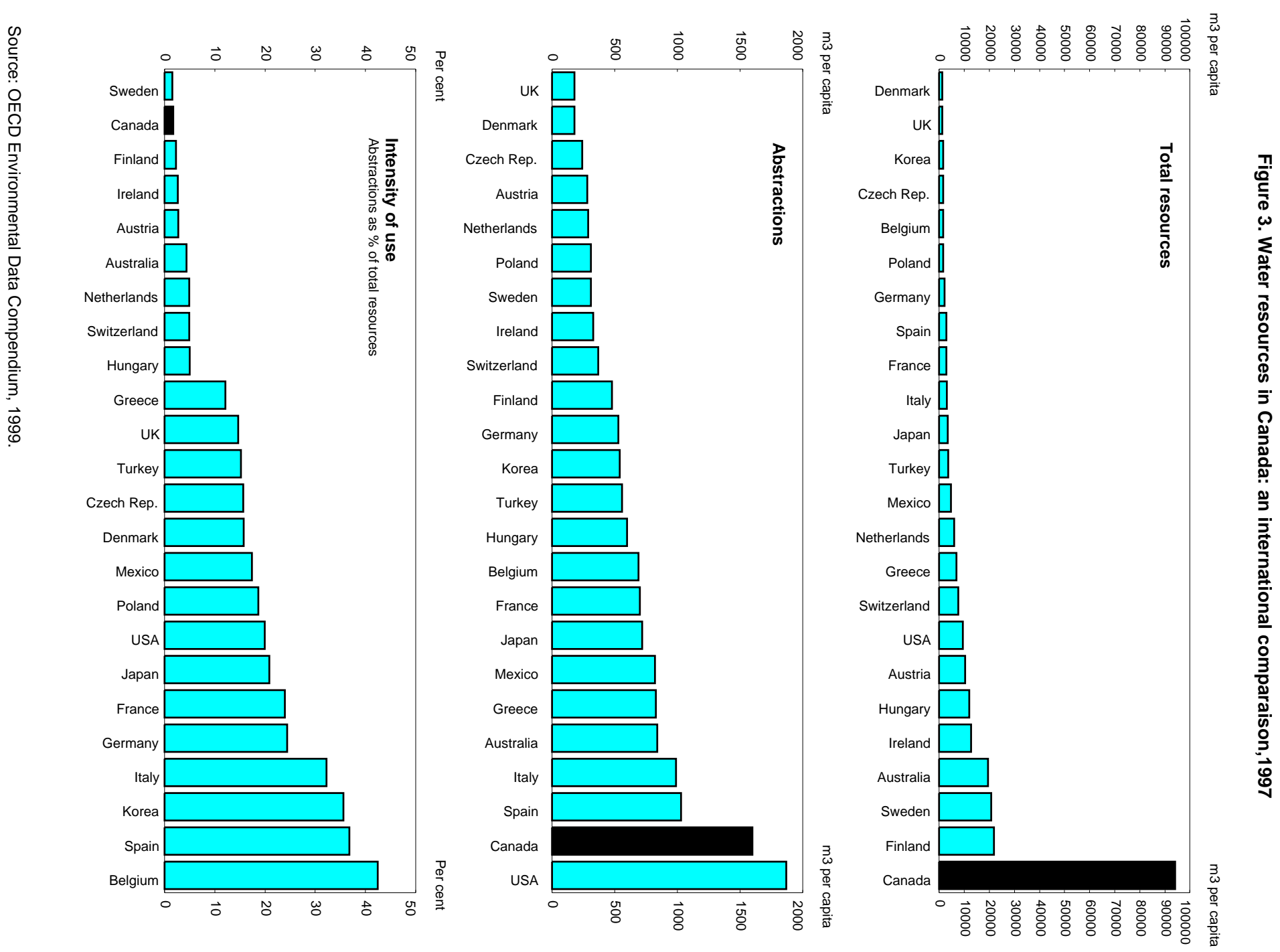
20. These systems do not allow an efficient allocation of water, even in periods of plenty, and their shortcomings become obvious during shortages. First, the rights are not allocated according to the relative net benefits of the proposed water use - opportunity costs are ignored. Second, since rights cannot be traded after being issued, their allocation cannot easily be changed if the relative value of alternative uses change (Renzetti and Dupont, 1999). This is particularly problematic when the water rights in a water basin have been fully allocated, because a new user or a user of "higher" value cannot get access to the resource. This problem is most striking in southern Alberta, where it is envisaged to make water rights transferable (see Box 1). Making rights transferable is the only way to achieve allocative efficiency when availability is limited. If transactions were to take place, they would also provide market prices for water and allow the estimation of the rent associated with its use.

21. Ideally, water pricing should cover both the (fixed and variable) cost of supplying water, the environmental costs of its extraction, and the associated rent. ${ }^{20}$ In Canada, however, water pricing is under-utilised as an instrument. In fact, despite some moves in that direction over the recent period, the pricing structure for water supplies is far from an "economic" approach with full-cost recovery and charges based on consumption. The federal government endorses such principles, but municipalities are in charge of water pricing. That water prices are low in Canada compared with other OECD countries is not surprising, as water is plentiful (Figure 4). However, they are far from covering even infrastructure costs. ${ }^{21}$ Such subsidisation is working against water conservation and also increases long-term capital and operating and maintenance costs. In the case of Ontario, for example, Renzetti (1999) finds that the gap between marginal cost and prices for municipal water supply has led to consumption exceeding efficient levels by an average of 50 per cent.

22. As in other OECD countries, subsidies are particularly important for agricultural uses. In the mid-1990s, the average water price for agricultural uses represented less than 3 per cent of even the modest average price paid by house-holds (OECD, 1999a). ${ }^{22}$ Even when taking into account all the necessary caveats in comparing prices - the quality as well as the transport costs of water used by farmers are lower than for households - the gap remains huge. Estimates indicate that subsidies for irrigation amount to about 90 per cent of supply costs. ${ }^{23}$ In recent years, many provincial water agencies have increased the use and levels of agricultural water charges, their aim being to cover about 60 per cent of operating and maintenance costs in 2000 .

20. While it is certainly legally possible to make users pay for the costs of supplying water and the environmental costs of extraction, this is less clear for the scarcity rent. Water rights have been initially granted for free in Canada, and taxing the rent ex post may raise legal issues similar to those experienced in the United States under the heading "takings" (see OECD, 2000c).

21. Figures from a report of the National Round Table on the Environment and the Economy (1996) indicate that subsidies covered more than one-third of the operational costs of Canadian water and wastewater services in 1994, and about two-thirds of capital expenditure.

22. On average, agricultural water prices ranged between $\$ 0.0017$ and $\$ 0.002$ per cubic meter in 1996, against \$0.7 for households in 1994 .

23. Calculations of implicit values of water rights in southern Alberta, using market prices of different types of land (irrigated or not) show that the availability of irrigation water adds approximately 35 per cent to land values (Veeman et al., 1997). 


\section{Box 1. Improving water allocation through water markets in Alberta?}

Alberta is probably the region where the highest potential gains could be expected from having water markets - the Alberta authorities prefer to refer to water transferability. Perhaps reflecting this fact, the province's water legislation was changed in 1996 to allow the transferability of water rights, but to this point in time, this has not yet occurred. Water rights are fully allocated in many river basins of southern Alberta, and licenses are tied to the land and use for which they were issued. As about 90 per cent of water use in southern Alberta goes to irrigation of agricultural crops during summer months (Horbulyk and Lo, 1998), this crowds out non-agricultural but possibly more valuable use.

The aim of the reform of the Alberta's Water Act is to bring some flexibility into the system, while avoiding the use of direct pricing mechanisms. In fact, the pricing provisions contained in the initial draft of the Water Act were removed during the five-year long public consultation process. Hence, the new Act does not allow the taxation of the rent associated with water use, but it will nevertheless increase the allocative efficiency of water consumption.

Water transfers envisaged by the government of Alberta would have the following characteristics: $i$ ) they would mainly concern surface water; $i$ i) they could be temporary or permanent; iii) they would be allowed across location and use (agriculture, industry and residential); and $i v$ ) they would be restricted at the river basin level, and possibly even at the stream level. According to Horbulyk and Lo (1998), this last restriction is not very constraining, as transfers at the river basin level would already allow society to reap 90 per cent of the potential welfare gains from water reallocation.

Transfers would be strictly regulated, as government approval would be required for every transaction for a number of reasons:

- To control for the possible impact of the transfer on the priority system. Water rights are operated with a seniority priority; shifting the location of a right and its attached priority could have significant impact on third parties (as in some cases one person's return flow is the next person's water right).

- To control for the impact that the change in use and location have on the water body and aquatic environment.

- To allow for public consultation.

Restrictions of this type are also common in places where such markets have been developed, in particular in Australia. The government would also have the possibility to hold back up to 10 per cent of the water being transferred to be left in the water source for conservation purposes. Uncertainty remains, though, on the type of public consultation mechanisms envisaged, and their possible impact in the decision to allow the transfer. While effective conflict resolution mechanisms have been found to be important (OECD, 1999b), it would be important to specify clear rules.

Uncertainty also remains regarding the timing for implementing the transferability of water rights. The legislation was proclaimed four years ago and came into force on January 1999, but the reform has not yet taken effect. Implementation is conditional on the development of water management plans, which are not expected to be completed prior to end-2001. Alternatively, before water management plans are established, transfers could be authorised by cabinet order, which has not been done. 
Figure 4. Water prices and residential water use Mid-1990s

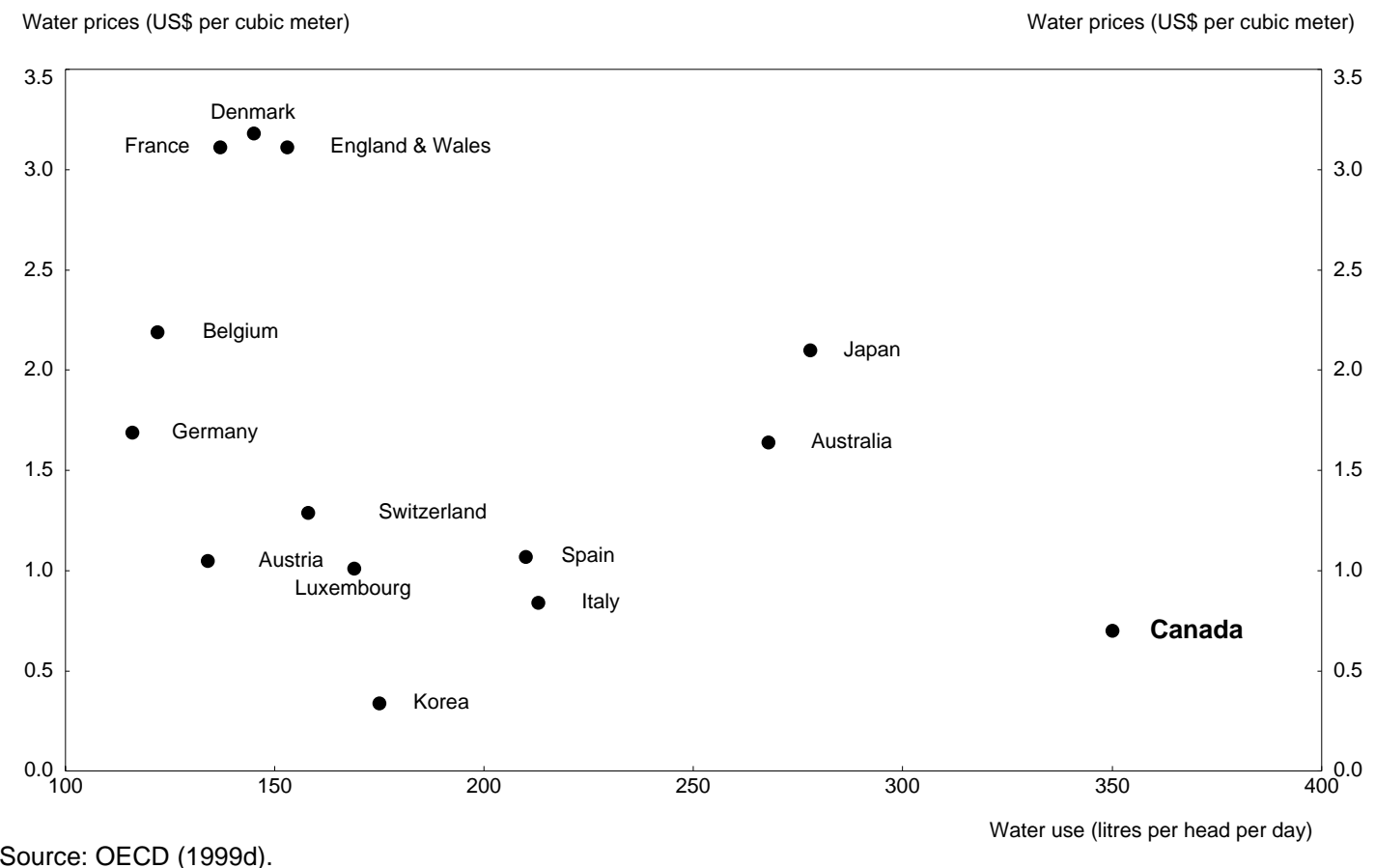

23. Rate structures are moving only slowly towards volumetric pricing for households and industries. The clear trend observed in most OECD countries away from flat-fee pricing for households consumption is much less pronounced in Canada. In fact, only 56 per cent of the households were metered in $1996 ;^{24}$ there would therefore appear to be some distance to go before metering turns out to be too costly at the margin compared with the benefits it provides. In any case, having the rate structure decrease with the quantity consumed - valid for 14 per cent of households in 1996 - should be immediately suppressed. Flat-rate tariffs are also widespread for industries, a rare feature in the OECD; metering would probably be cost-effective in all such cases.

24. The rent associated with water use is also obviously not directly taxed. That deficiency is most questionable for the agricultural sector, as a much smaller share of the water used for irrigation is returned than for most other uses. The question is also topical for electricity production. Hydropower plants are generally charged a misnamed "water rental" based on the kilowatt-hours of electricity produced (between 0 and 0.50 cents per $\mathrm{kWh}){ }^{25}$ As hydropower resources have been developed by provincially owned monopolies with a mandate to supply power at cost, provinces charge far less than the economic rent. The

24. Metering is more prevalent in Ontario and the Prairies than in other regions of the country.

25. In Ontario, the charge is 0.39 cents per $\mathrm{kWh}$, corresponding to one tenth of the average wholesale price. 
rent issue is becoming much more topical, though, with the recent deregulation and privatisation of the sector in Ontario, and the government is actually consulting with the companies to adopt a new approach to setting water charges.

\subsubsection{Water exports}

25. Water exports have been high on the political agenda lately. The issue is not new, as a number of ambitious and controversial schemes for diverting Canadian rivers towards the United States have been put forward in the past. The recent debate, however, was spurred by an increasing number of proposals and applications in Newfoundland, Ontario and Quebec to ship water by marine tankers, mostly to Asia or the Middle East. ${ }^{26}$ As Canada is well endowed with water resources and water is rare and therefore highly valued in other countries, exports of water could represent a potential economic opportunity for the country. For a number of reasons, however, the opposition to such bulk exports has been large and, in February 1999, the federal government announced a strategy to prohibit the bulk removal of water from Canada. Acting within its jurisdiction, the federal government introduced amendments to the International Boundary Waters Treaty Act which would prohibit bulk removal of water from Canadian boundary waters, principally the Great Lakes. This was based primarily on water quantity obligations under the 1909 Canada-US Boundary Waters Treaty, and secondarily on the need to preserve the integrity of water basin ecosystems. The federal government is also working on a federal-provincial accord that would prohibit the bulk removal of water, including for exports, from major drainage basins. In fact, all provinces have put into place, or are developing legislation and policies to prohibit bulk water removal.

26. The relevant public debate is sometimes rather emotional. There are three main underlying issues: opposition to the "commodification" of water; a fear of the potential social and environmental consequences of large scale "out-of-basin" water transfers; and fear that international trade rules may prevent restrictions on exports in times of water shortage.

27. Water is a common property resource, and environmental groups and other citizens' groups are campaigning for banning bulk water exports, arguing that they would gradually make water "a commodity as the others", which private companies would try to control in order to make a profit, and that ultimately water may only be available to those able to pay for it. ${ }^{27}$

28. Environmental concerns have played an important role in Canada's approach to protecting freshwater resources. Bulk removal of water may have varying impacts on the ecological integrity of a basin, ranging from negligible in some cases to significant in others. This depends on a number of factors such as the amount of water being removed in relation to the volume of water available, existing water demand and uses, and the seasonal, annual and long-term variability in water levels and flows. The prohibition of all bulk water removal is based on a precautionary approach, particularly in the face of the risk of more significant cumulative impacts of removals on the ecosystems and communities dependent on these watersheds, and potential effects of climate change on water availability and distribution.

29. A good example of the concerns about environmental consequences of bulk water removals is provided by the March 2000 report of the International Joint Commission (IJC), the body dealing with all Canada-US boundary water, including the Great Lakes - the main potential source of exports. ${ }^{28}$ An average

26. The projects in question were subsequently cancelled, and all three jurisdictions have adopted regulations or laws that prohibit the bulk removal of water.

27. See, for example, the websites of the Canadian Environmental Law Association (http://www.web.net/cela/) and the Council of Canadians (http://www.canadians.org/).

28. The report is available on the IJC website (http://www.ijc.org). 
of less than 1 per cent of the waters of the Great Lakes is renewed each year by precipitation, surface water runoff and inflow from groundwater sources. In the face of uncertainty about the availability of Great Lakes water in the future, in particular as climate change may lower the Great Lakes levels and flows, as well as uncertainty about the environmental consequences of water removals, ${ }^{29}$ the IJC advocated a precautionary approach and recommended very restrictive rules for bulk removals, which would make it virtually impossible to engage in large-scale, long distance bulk removal from this source.

30. The perception that international trade agreements may limit governments' ability to control water exports has also played a role in the debate. Water in its natural state is not covered by the WTO Agreement or the North American Free Trade Agreement (NAFTA), but provisions regarding export restrictions may apply if water that has been extracted is turned into a tradeable good. ${ }^{30}$ Although they prohibit quantitative restrictions, the GATT and NAFTA provide for exceptions, in case of threat to human, animal or plant life or health, or for the conservation of an exhaustible natural resource. In these cases, however, the non-discrimination principle would have to prevail, and exports may have to be restricted, for instance, by means of a proportionality requirement. In this case, the proportion of exports to total shipments would have to be maintained. This would imply that, if a precautionary approach dictates reduced water extraction, domestic consumers would have to suffer cuts together with those countries importing Canadian water.

31. A moratorium may be justified in the short run to clarify the implications of free-trade agreements and try to assess more precisely the economic and environmental costs and benefits of bulk water removals. In the longer run, it may be possible to design an export licensing regime that would take into account environmental concerns and provide for the possibility of interrupting trade flows in case of environmental problems, while giving Canada the opportunity to reap some benefits from water exports. ${ }^{31}$ If permits are provided for that purpose, Canadian governments should ensure that they extract the associated rent. A "restrictive" licensing system, ${ }^{32}$ if judged necessary by the authorities due to environmental costs, would in any case probably discourage potential buyers that need a guaranteed supply. ${ }^{33}$ As for the distributional concerns, water exports, or the pricing of water in general, does not prevent governments from ensuring that every Canadian has continued access to plentiful clean water.

32. In sum, there is a paradox in Canadian attitudes to water management. On the one hand, prohibition of bulk water removal underlines the high value put on water; on the other hand, there is a

29. This is the case in particular for the groundwater system, about which relatively little is known.

30. The IJC, an independent bi-national panel, also investigated the issue of trade considerations. After hearing from various citizens groups, and government and independent trade law experts representing every point of view, the IJC came to the same conclusion as Canada and the USA that trade agreements do not apply to water in its natural state.

31. A recent poll indicated that Canadians would agree to water exports as long as the government "controls the tap" (The Globe and Mail, 15 December 1999).

32. As environmental effects depend in large parts on the scale of the removals, they could be controlled in a licensing system (as they are currently at the domestic level). Permits could, for example, be provided on a one-off or fixed-term basis.

33. The failure of the proposal to tanker water from British Columbia to the Californian city of Santa Barbara at the start of the 1990s may be illustrative in this regard. There were several reasons why Canadian firms were not competitive, but one was the lack of credible seller commitment (Smith, 1994). 
strong reluctance to recognise this value by allowing proper pricing that would enhance water conservation and allocative efficiency, and cover the cost of infrastructure. ${ }^{34}$

\subsection{The Atlantic groundfisheries: an example of conflicting policies}

33. The Canadian fisheries, and in particular the Atlantic groundfishery, ${ }^{35}$ provide an illustration of how well-intentioned policies may contribute to over-exploitation of a common resource. Other factors played a role in the 1992 collapse, such as particularly unfavourable environmental conditions and overfishing by foreign fleets. Policy setting is complicated by the difficulty of disentangling regional and social issues from the protection and renewal of the resource. Some regional and social policies have the perverse effect of increasing incentives to remain in the fishing industry, while resource management policy is trying to reduce fishing capacity. This section analyses these issues focusing on:

- The origins of overfishing and the inability of policy in the 1970s and 1980s to address the "common pool" problem.

- The political response to the collapse, with programmes to support fishers and plantworkers and to reduce the number of fishing licences, as well as longer-term reforms of management practices with the introduction of property rights management and co-management.

- The inconsistency of the signals provided by social policies notably (un)employment insurance, and some management decisions taken in fisheries other than groundfish, with the stated objective of reducing overcapacity.

\subsubsection{The origins of the problem}

34. In 1992, the stocks of groundfish, the mainstay of the Atlantic fishery, were so depleted that it had to be closed to commercial fishing, with only partial re-openings since 1995 . The consequences of this collapse have been severe, particularly in Newfoundland where fishing and fish processing have traditionally been the core economic activities and unemployment is chronically high. Environmental factors, such as changes in ocean temperature and salinity were at play in this crisis, ${ }^{36}$ and overfishing from foreign fleets also had a role. There is nevertheless a widespread recognition that overfishing from Canadian fishers has played a part, and that past policies contributed to the collapse (see Box 2).

34. In fact, another problem associated with water removals is the absence of prices reflecting its "true" value, which makes it difficult to assess the opportunity costs of exports and to make projections on future values, since even today's value is not known.

35. The circumstances of the Atlantic groundfishery is not illustrative of the entire industry, which comprises about 160 distinct fisheries. Stocks are also diminishing in the Pacific salmon fisheries. However, the situation results from different factors, and overfishing has probably played less of a role. In addition, the consequences of the salmon crisis there are less acute than in the Atlantic region, because the economy is more diversified. Adjustment policies have resulted in the Pacific salmon fleet being reduced by 50 per cent since 1995 .

36. Changes occurred in the natural environment. Temperatures fell and ice coverage expanded. The water also became more saline. This has affected the survival capacity of fish as well as the predator-prey balance (reducing the number of prey available for groundfish but increasing the number of predators such as seals). These factors are probably still at play, as no substantial increase in stocks has been observed in the eight years of closure. 


\section{Box 2. The collapse of the Atlantic groundfishery}

A number of factors led to catches exceeding sustainable yields and to the resulting collapse of groundfish stocks in Atlantic Canada.

Harvests have been regulated by the Department of Fisheries and Oceans for a long time in Atlantic Canada, but total allowable catches (TACs) were set systematically higher than required to conserve the resource (Report of the Auditor General of Canada, 1997). As early as 1986, scientists began to become aware that they had been greatly overestimating the size of stocks. This over-estimation reflected in part an incomplete understanding of the biology of fish stocks and data limitations. Prediction errors were compounded by a decision-making process that failed to take uncertainty into account, as decision-makers were allowed substantial flexibility vis-à-vis the scientific recommendations (see Annex II). Canada, as other countries, at the time did not follow a precautionary approach to fisheries management.

Competition among fishers led to a "race for fish" and the over-investment "trap" observed in many parts of the world, which makes for more forceful resistance to TAC reduction and enforcement, not to say to shrinkage of the sector. Overfishing by foreign vessels in the area adjacent to the Canadian 200-mile limit has also contributed to the decline in fish stocks.

The large subsidies provided to Canada's fisheries have exacerbated the overfishing problem by increasing both employment and investment in the sector and creating pressures on resource management decision-making and implementation (see Annex II). Some of the subsidies directly favoured the development of the sector. Until the mid-1980s, the federal and provincial governments provided loans and loan guarantees to build and purchase boats and to buy new gear to improve fishing technology. Fuel purchase was also exempt from the provincial fuel tax. Other subsidies were provided to compensate for declining profitability resulting from the "race for fish". In the mid-1970s, inshore fishers and fish-processing companies were supported by a temporary assistance programme, and at the start of the 1980s, the fishprocessing firms were temporarily nationalised to avoid bankruptcy. Finally, but not least importantly, the easy-eligibility conditions of the unemployment insurance for fishers also contributed to maintaining overcapacity. Table 1 shows the growing dependency of fishers and fish-processing workers on unemployment benefits

Table 1. Unemployment insurance benefits

\begin{tabular}{lcc|cc}
\hline & \multicolumn{2}{l|}{ Per cent of fishing income } & \multicolumn{2}{l}{ Per cent of total income } \\
\hline Self-employed fishing & & & & 34 \\
$\quad$ All Atlantic & 43 & 81 & 21 & 47 \\
$\quad$ Newfoundland & 96 & 160 & 31 & 33 \\
& & & & 57 \\
Fishing processing & 30 & 63 & 21 & 30 \\
$\quad$ All Atlantic & 48 & 94 & & \\
$\quad$ Newfoundland &
\end{tabular}

Source: Report of the Auditor General of Canada (1997). 


\section{Box 2. The collapse of the Atlantic groundfishery (contd.)}

It is no surprise in this context that regulations put in place in the 1980s to limit entry into the groundfish Atlantic fisheries failed to do so. In fact, the number of vessels increased over that decade, while in the inshore fisheries, fishers responded to limits on the number of vessels by increasing the use of unrestricted inputs, improving their catching power. Input substitution in the fisheries concerned as well as spillover effects on other fisheries have shown the limits of this form of management based on "command and control" regulation.

\subsubsection{The response to the problem: a progressive recognition of the necessity to reduce the capacity}

35. Since the closure, conservation measures aimed at rebuilding the stocks have underlied fisheries management policy. The main programmes implemented in response to the crisis were the Northern Cod Adjustment and Recovery Program (NCARP) in 1992 and the Atlantic Groundfish Strategy (TAGS) in 1994, the latter including a stated objective to reduce harvesting capacity by at least 50 per cent. ${ }^{37}$ Measures used for this purpose included the buy-back of licenses, early retirement and training. Overall, about C $\$ 3.5$ billion were spent through these programmes between 1990 and 1998, when TAGS ended, but income support and employment insurance have had the lion's share, accounting every year until 1996 for more than four-fifths of federal assistance to the sector (Figure 5) ${ }^{38}$ As of end-1998, the sums spent on buy-backs had served to retire only 1300 groundfish licenses, that is slightly less than 10 per cent of the total outstanding in 1994. An international comparison shows that for 1996, the most recent year available, Canada's aggregate fisheries support remained one of the highest, in relation to landed value, among OECD countries, largely reflecting the substantial adjustment expenditure (Figure 6).

36. Recognising the necessity to reduce both capital and labour in the sector, the federal authorities have focused their latest programme, the Canadian Fisheries Adjustment and Restructuring (CFAR) scheme, announced in June 1998, measures aimed at achieving permanent exit from the fishery. An amount of C\$ 730 million is to be spent by 2001 in the Atlantic and Pacific regions on licence retirement, early retirement, final cash payments, adjustment measures for labour and economic development measures (see Annex II). Up to now this has allowed the retirement of 1857 more licences and 1800 older harvesting and processing workers. Overall, since 1993, the number of groundfish licenses has been reduced by 47 per cent.

37. To help address the common pool problem and past failures of regulations to limit capacity, the government has also been reforming management practices, extending in particular the use of individual quotas systems. As they provide the fishers with a right to a specified share of the annual total allowable catch, these systems encourage more orderly harvesting by stopping the "race for fish" and thus remove the incentive for over-investment. In addition, when they are transferable, they allow for an efficient self-rationalisation of the sector, as lower-cost operators can buy quotas from their higher-cost rivals and increase the overall profitability of the fisheries. In Canada, the first major quota system was introduced for the offshore groundfish fleet as early as 1982, but transferability was allowed only in the 1990s. Individual

37. The others were: the Atlantic Fisheries Adjustment Program (AFAP) and the Quebec Federal Fisheries Development Program (QFFDP) in 1990, and the Atlantic Groundfish Adjustment Program (AGAP) in 1993.

38. In fact, when the sum available for income support turned out to be insufficient for the number of eligible individuals, all the non-income support measures contained in the TAGS were cut. 
quota systems have been gradually introduced in other offshore and inshore fisheries, mainly for fleets of medium-and large-size vessels, and in 1999, they covered about 50 per cent of the total landed value of fish. Scope may remain, though, for extending this share, which covers all major commercial species in some other OECD countries such as Iceland and New Zealand. ${ }^{39}$ Inshore ground fisheries, in particular, have been left out of property-rights-based management. ${ }^{40}$

Figure 5. Federal government assistance to the Atlantic fishery C\$ millions

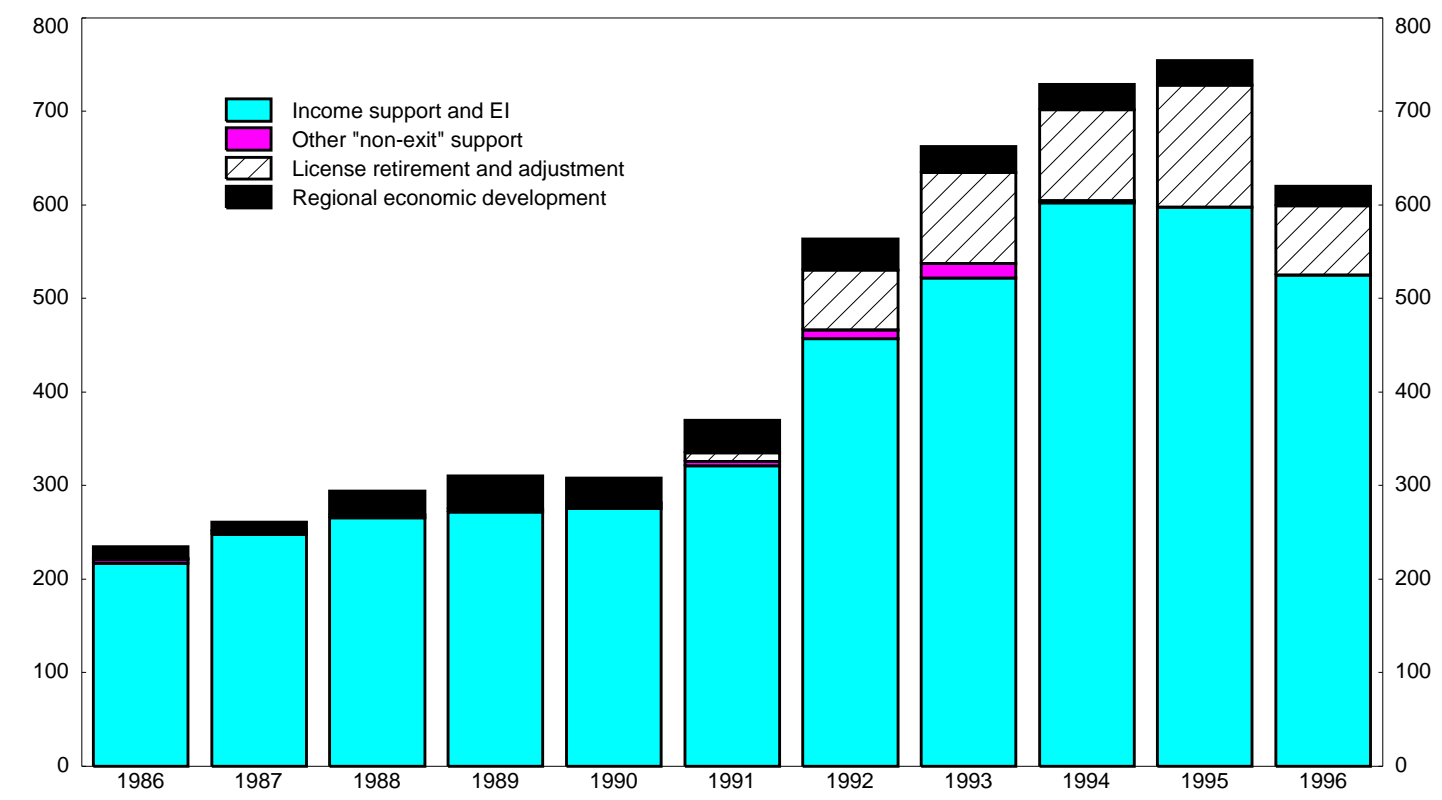

Source: OECD (2000), "The Impact on Fisheries Resource Sustainability of Government Financial Transfers: Case Studies", OECD Committee for Fisheries, http://www.oecd.org/agr/fish/doc/fi0010.pdf.

39. Regarding inshore ground fisheries, and IQ management, there is no example of a country that would have converted inshore fisheries with 10000 users with small boats. Moreover, the only large and profitable fishery that is not an IQ in Canada is lobster and it would be most difficult to put lobster under IQ.

40. The decision whether to use property rights management is left to fishers, with in general a two-thirds majority rule required for implementation. 
Figure 6. Government transfers to marine fisheries (1) Percentage of total landed value, 1996

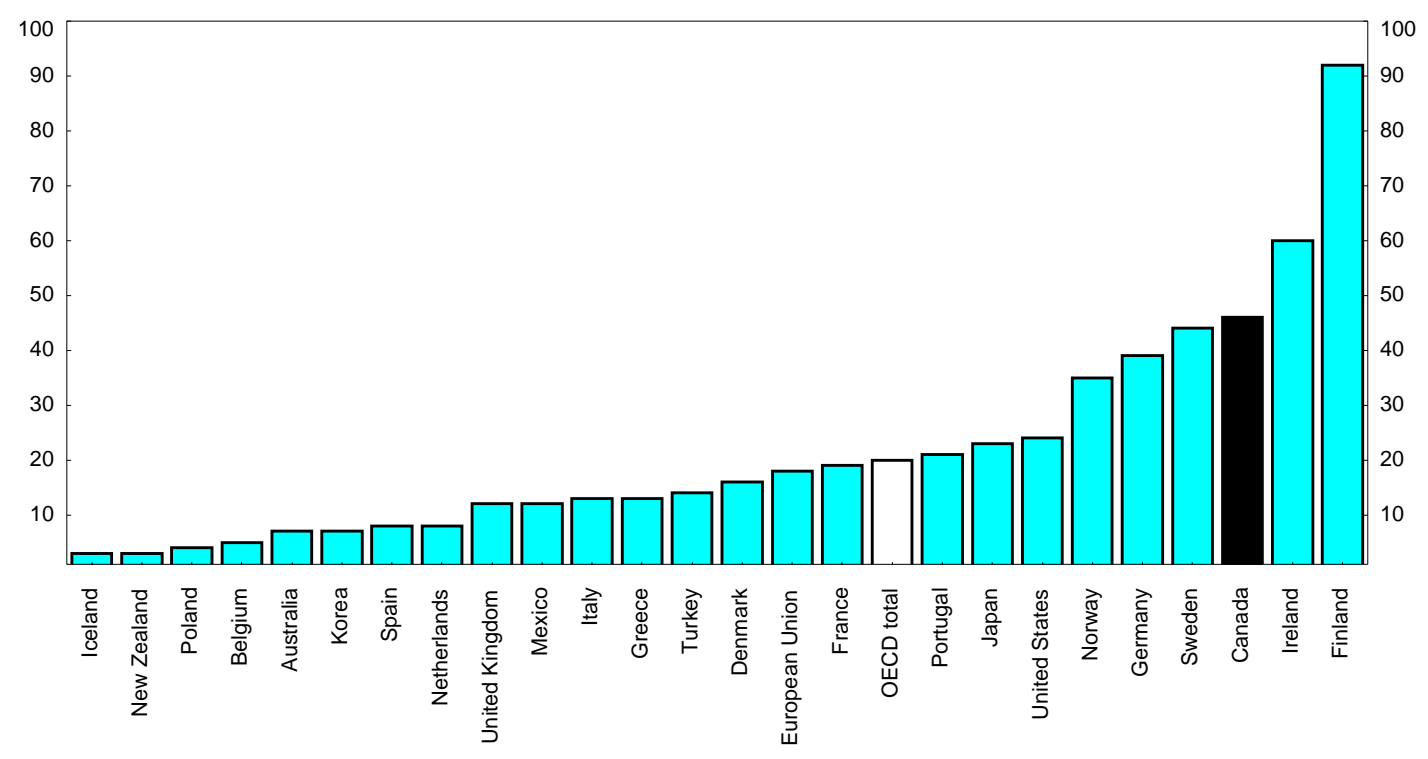

1. Financial transfers to marine capture fisheries,i.e. excluding inland fishing, aquaculture and fish processing. Source: OECD (2000), Transition to Responsible Fisheries, Paris.

38. As for other types of fisheries management, to be effective, individual transferable quotas (ITQs) require a properly functioning monitoring and enforcement system. A problem specific to ITQ management systems is that fishers face incentives to discard the least valuable fish to maximise the value of the catch against quota, a practice which has been noted to have increased since the introduction of ITQs (Fisheries Resource Conservation Council, 1997). In his 1997 and 1999 reports, the Auditor General also pointed to weaknesses in controls over dockside monitoring and enforcement capacity. Controls at sea are indeed costly to implement when there is a large number of small vessels.

39. In part to remedy this type of problem, the federal government has also promoted the co-management of the fisheries, another longer-term reform of management practices. Co-management consists of providing harvesters with a greater decision-making role as well as more responsibility for the costs of resource conservation and management through charging, both in fisheries managed with individual quotas and others. In the longer run, the objective is also, under the framework of the 1997 Canada Oceans Act, to integrate fisheries management with that of other activities based on the ocean resource (see Annex II). While in principle co-management should enhance the cost-effectiveness of fisheries management, there seem to be some weaknesses in the current system. First, the accountability of cost-sharing arrangements appears limited and industry is not really involved in decision making (Report 
of the Auditor General of Canada, 1999). Second, the charging system lacks a clearly established basis, which prevents it from delivering all its potential beneficial efficiency effects. Third, the Department of Fisheries and Oceans is also limited in its legal authority to enter into real partnership with fishers under the current Fisheries Act.

40. There are two main theoretical reasons for establishing user charges in the fishing industry. One is to recover the costs associated with fishery management, such as administration, research, monitoring and enforcement, instead of paying it out of general taxation. Provided there is adequate opportunity for consultation with industry, recovery of costs should increase the efficiency of management services, as it creates a link between the primary beneficiaries of services and the costs of providing them. Appropriately structured charges can also make the industry operate at an economically optimal level of activity, discouraging fishing effort from becoming excessive. A second reason for introducing charges is to extract the resource rent associated with the property rights, or access rights, provided to fishers, through, for example, auctioning of quotas or license fees. Theory suggests that this will not affect the market's allocative efficiency, but will have distributional consequences. Up to now, quotas have never been auctioned, but some of them bear a fee per tonne of quota.

41. A problem with the Canadian approach to charges is, however, that it does not clearly distinguish between user charges and rent taxation and is not consistent across fisheries, in contrast with Iceland and Australia, for example. The types of costs recovered from industry are quite varied (Report of the Auditor General of Canada, 1999). ${ }^{41}$ According to the Canadian authorities, charges more systematically related to the costs of managing each fishery (at least the specific costs) would result in unwanted distributional effects, as high-cost low-rent fisheries would be charged more than their low-cost high-rent counterparts. Hence, the current charging system only achieves partial recovery of total management costs across all fisheries, as opposed to cost recovery on a fishery-by-fishery basis (Kaufmann and Geen, 1997), which is required to improve efficiency in the provision of management services.

42. The Department of Fisheries and Oceans is also developing - in collaboration with the fishing industry - a Canadian Code of Conduct for Responsible Fishing, within the FAO framework. The code will set general principles and guidelines for all commercial fishing operations in Canadian waters, allowing for more co-operative management of fisheries and greater involvement of the industry itself in achieving sustainable management of the resource. ${ }^{42}$

\subsubsection{The challenge: integrating social and economic policies}

43. The 1996 employment insurance reform had as one objective a reduction in the frequency of use of the system, by lowering benefits and tightening eligibility requirements, which might have been expected to encourage fishers to exit from the sector. ${ }^{43}$ However, to date, the impact on this group seems to have been limited in practice (see OECD 2000b, Chapter III). Indeed, eligibility conditions appear to have been eased rather than tightened, through multiple claims provisions, while the regional differentiation of benefits continues to deter mobility. In fact, total benefits paid to fishers have not declined significantly since the 1996 reform. $^{44}$ While the latest adjustment programme (CFAR) has no income-support

41. Charges are currently calculated as 2 per cent of landed value.

42. Greater involvement of the industry is important to achieve effective management. This is particularly the case for the fisheries comprising a large number of small vessels as it reduces the monitoring and enforcement costs.

43. Employment insurance legislation has a specific section for fishers.

44. Total benefits paid to fishers declined in the fiscal year 1996/97 due to the reduction in maximum insurable income. However, they increased in the following year, mainly as a result of increased multiple claims for 
component, when the TAGS programme came to an end in August 1998, weeks of TAGS income support were counted as labour-force attachment to allow qualification for employment insurance. However, data show encouraging signs of changing behaviour, especially among younger fishers. ${ }^{45}$

44. According to an evaluation conducted in 1998, the TAGS labour adjustment measures - which were abandoned in 1996 when funds were switched towards income support - had little success in reducing dependency on unemployment benefits, and in increasing exit from the fisheries sector (see Annex II). The labour adjustment measures included in the CFAR have not been evaluated yet. As for the regional economic development components, only since 1999 have the relevant programmes aimed at avoiding investment in fishing and processing of other species, thereby allowing real diversification away from the fisheries.

45. In fact, in the Newfoundland region in particular, harvesting capacity has increased dramatically in the shellfish fisheries, both in the form of new large vessels and upgrading of existing vessels. By and large, this growth is attributable to increased abundance of shellfish stocks since the 1980s due to changes in environmental conditions including water temperature and salinity. In some shellfish fisheries, however, the recent increase in harvesting capacity results partly from management decisions taken for unspecified social concerns (Report of the Auditor General of Canada, 1999) that conflict with conservation objectives. In some instances, the scientists' recommendations for TACs were not followed. In one case in Newfoundland, TACs were increased contrary to the scientists' recommendations, in order to issue new entrants with temporary quotas (of a size so small as to be incompatible with economic viability), mainly for small boats particularly affected by the closure of the groundfish fisheries. ${ }^{46}$ These changes are damaging to individual quota programmes, as they undermine the security of property rights. They also provide the wrong signal, encouraging increased harvesting capacity despite uncertainty about how long the increase in stock will last.

46. In sum, despite the recognition of the necessity to reduce overcapacity in the Atlantic fisheries ${ }^{47}$ as well as dependence on government transfers, notably employment insurance ( $c f$. Department of Fisheries and Oceans, 1999) in order to make fisheries ecologically sustainable and economically viable, policies have tended to send conflicting signals and have hampered the achievement of these objectives. The federal nature of the Canadian political system has also played a part in slowing the response. Jurisdiction over fisheries is shared, the federal authorities being responsible for fish harvesting and the provinces for fish processing. One result, as demonstrated by Schrank (1996), is that even when the federal authorities have tried to take a firm stand to reduce some subsidies, for example, provinces have prevented the implementation of that policy. Moreover, the fact that unemployment insurance is paid by the federal government, and not from the provinces' budgets, may also contribute to the provinces' resistance to any change in the system that would result in increasing their own expenses in the area of social welfare.

winter and summer seasons (amounting to C\$ 215 million in 1997-98 only 1 per cent less than two years earlier).

45. Claims for the under-25 age group decreased 20 per cent between 1995/96 and 1998/99.

46. The example referred to is that of the Newfoundland snow crab fishery. Another example where scientists' recommendations were not followed is that of the Bay of Fundy scallop fishery (Report of the Auditor General, 1999).

47. In 1997, the Fisheries Resource and Conservation Council estimated that in some instances, capacity was two to three times larger than needed. Estimating over-capacity, though, is not a simple task as it involves biological, technical and economic judgements. 
47. The Atlantic Fisheries Policy Review, launched in May 1999, aims to address some of these issues by establishing a cohesive policy framework to guide fisheries management. ${ }^{48}$ Developed by the Department of Fisheries and Oceans in consultation with stakeholders and provincial governments, the review seeks to consolidate current management policies, clarify direction where there are competing priorities and establish a set of principles. The recently announced Oceans Management Strategy, which adopts an integrated approach involving all government levels as well as all potential users with the creation in particular of protected marine areas and integrated management programmes (see Annex II), may also have an effect on fisheries management. However, both initiatives are still in their development phase, and it is difficult to be sure at this stage what their impact will be on fisheries management. A further challenge for policy makers, however, is to integrate social and economic policies more generally, in order to avoid having conflicting incentives in place, thereby preventing the achievement of stated objectives.

\section{Environmental policy challenges}

\subsection{Dealing with pollution}

48. As noted, because of the size of the country, environmental pressures are low in Canada, compared with most OECD countries, but resource-based activities are generally pollution intensive and cause problems in some cases. Important progress has been achieved regarding air, soil and water pollution in some areas, such as the Great Lakes, the St. Lawrence River and the Fraser River. The recently developed Pilot Environmental Sustainability Index actually puts Canada in the top quintile of the world's nations, although difficulties in interpreting such indicators imply a need for caution. ${ }^{49}$ However, problems remain in particular areas, both in terms of environmental and cost-effectiveness.

49. The polluter pays principle has been established for some time as one of the basic ways to promote a coherent approach to environmental problems. ${ }^{50}$ In Canada, this principle is not systematically applied. Instead a variety of ad hoc approaches is employed, both in setting targets and standards and in their enforcement. Reductions in funding - which have for the most part occurred without corresponding reductions in the level of ambition of policy targets - have also reduced the authorities' enforcement capability. Increasingly frequent recourse to voluntary agreements, with the concomitant danger that they are used not only to reduce the cost of meeting targets but have the practical effect of weakening them, is partly a result of these reductions. Economic instruments are also rarely employed, partly because of a political reluctance or inability to impose new taxes, although some recent proposals, such as the "cap-and-trade" scheme for emissions of sulphur dioxide and nitrogen oxide in Ontario (see below), reflect a recognition of their effectiveness. This section presents examples of the variety of policies used to deal

48. The Atlantic Fisheries Policy Review is part of the "Fishery of the Future" strategy, which also includes policy guidelines for the Pacific coast salmon fisheries.

49. The index measures the extent to which a country achieves environmental sustainability by looking at five areas: the extent to which environmental systems are maintained at healthy levels, and improving rather than deteriorating; the level of anthropogenic environmental stress and risks; human vulnerability to environmental impact; social and institutional capacity to deal with environmental challenges; and environmental co-operation with other countries (World Economic Forum, 2000).

50. The Polluter Pays Principle (PPP), adopted by OECD countries in 1972, has evolved over time. Initially, it meant that the polluter should bear the costs of pollution prevention and control. Since then, it has been extended to cover administrative costs, and the costs of damage when the measures ordered by the authorities have not been taken, or those resulting from accidental discharge. Gradually, the PPP has tended to move towards the full internalisation of the external costs of pollution. 
with a number of problems, showing that where either the polluter pays principle is not applied or economic instruments are not used, it is very difficult to achieve both environmental and cost-effectiveness. ${ }^{51}$

\subsubsection{Toxic substances}

50. Toxic substances released into the air, water and soil are a shared jurisdiction in Canada. They fall under the umbrella of three relevant pieces of federal legislation: the Canadian Environmental Protection Act (CEPA), the Pest Control Products Act (PCPA) and the Fisheries Act. The federal departments concerned must work with their provincial counterparts, who have jurisdiction over the industry sector and agricultural practices. Provinces also have their own laws covering toxic substances. However, in this area, the role of the federal government is more important than for other polluting substances, due to the health dimension. A number of recent reports, in particular the 1999 report of the Commissioner of the Environment and Sustainable Development, have identified important weaknesses in the federal management of toxic substances.

51. The first weakness concerns the evaluation of the risks associated with such substances (Report of the Auditor General of Canada, 1999). There seems to be a substantial divergence of views among the various federal departments about such risks, with schematically the "environment-friendly" departments on one side (environment, fisheries and health) and the "business-friendly" ones on the other (natural resources, industry and the pest regulatory authority). The ensuing lack of co-ordination of research among the various departments and their different interpretation of legislation have led in many cases to indecision and inaction, as well as to inefficient use of federal resources. This points to the lack of a mechanism for decision-making. The federal budget cuts have also made it difficult for the services concerned to meet growing demand. For example, the re-evaluation of pesticides, whose need has been recognised for more than 10 years, has not been conducted due in part to a lack of resources.

52. The 1999 Report of the Auditor General also questioned the effectiveness of some policy measures. For example, a number of toxic substances were identified for virtual elimination in 1989, but federal departments have not yet developed a plan for eventually meeting this objective. The consultation processes launched with a number of industries to recommend management tools for substances listed in the legislation as highest priority provide another example where concrete action has followed only slowly. In general, the federal government's policy in this domain has been based mainly on voluntary measures, and this approach seems to have failed to provide the proper incentives to achieve the established targets.

53. In fact, as in other OECD countries (see Box 3), voluntary measures have shown their limits in achieving cost-effective reduction in pollution, due not least to accountability and enforceability problems. The main voluntary agreement is the Accelerated Reduction/Elimination of Toxics accord (ARET), a government-industry agreement initiated in 1994, which involves firms producing about 40 per cent of Canadian industrial output. In addition, nine agreements have also been negotiated between the federal government and targeted industries. ARET participants have reported large reductions in their emissions of toxic substances, but these cuts are not subject to any independent verification. This is also the case for all but one of the agreements with particular industries, which generally do not have measurable targets and cover only a small share of their sector. The Responsible Care Programme, initiated by the chemical industry, is an exception, as it is characterised by relatively ambitious targets, strict control procedures and a high level of participation. A shortfall common to all these agreements, however, is that they do not specify actions or sanctions to be taken in case of non-compliance with performance objectives.

51. A policy measure proves effective if it meets its target. It is cost-effective if the target is achieved at minimum cost. 


\section{Box 3. Voluntary agreements: the international evidence}

The OECD has recently conducted an evaluation of voluntary approaches for environmental policy $(\mathrm{OECD}, 1999 c)$. In general, the environmental effectiveness of voluntary approaches, and in particular negotiated agreements (involving commitments elaborated through bargaining between an industry and a public authority), is found to be modest.

First, the evidence points to the central role of the industry in the target-setting process, the scope for deficient participation of firms (free riding) and the uncertainty over regulatory threats, leading to generally rather unambitious goals. Second, at the implementation stage, negotiated agreements perform poorly due to non-enforceable commitments, poor monitoring and lack of transparency. In addition, as far as economic efficiency is concerned, it seems that the burden-sharing between firms is more driven by equity considerations than by cost-efficiency concerns, and that voluntary agreements do not rely on price mechanisms to induce pollution abatement. Finally, the usual claim that negotiated agreements tend to reduce administrative burdens is not confirmed either by empirical evidence or analytical arguments.

An evaluation conducted by Krarup (1999) on voluntary agreements in energy policy in some European countries (Denmark, Germany, France, the Netherlands and Sweden) also provides similar conclusions. While the agreements reviewed had clear targets, no business-as-usual estimation had been carried out before the schemes were implemented. In the end, targets were achieved, but they were found to correspond to outcomes that required no behavioural changes. Some of the agreements had achieved significant abatement but at a high cost, while others had low effects at low cost.

OECD (1999c) provides some policy recommendations. Voluntary approaches can play some beneficial role when used as complement to traditional command-and-control systems, as they allow for some flexibility in meeting targets. Although it has been rarely implemented up to now, voluntary agreements may also be mixed with economic instruments. However, the target itself should be set outside the negotiated agreement, as in some of the Dutch agreements, for example. Possible safeguards against the main drawbacks of voluntary approaches include: clearly established targets, characterisation of a business-as-usual scenario, credible regulatory threats, reliable monitoring, penalties for non-compliance and third-party participation in the process of setting objectives and performance monitoring.

54. The penalty threat in case of non-compliance with federal regulation also sometimes appears to lack credibility. Shortfalls in enforcement of federal regulations related to toxic substances were also identified by a parliamentary committee in 1998 (Standing Committee on Environment and Sustainable Development, 1998). First, enforcement capacity has been reduced following budget cuts. ${ }^{52}$ At the same time, the workload has been increasing, due in part to the growing share of pollution coming from smaller and more diffuse sources (farms, households, sewage plants) and to more sophisticated regulations. This combination, in turn, partly explains the increasing reliance on voluntary approaches.

55. In a number of instances, enforcement problems have stemmed from jurisdictional conflicts between the pollution permits granted at the provincial/territorial level and the federal legislation, as provincial/local authorities may be more subject to regulatory capture by business interests. ${ }^{53}$ When there is federal-provincial co-ordination, such as under the federal-provincial agreements that were negotiated to streamline administration and regulatory activities, enforcement was also found to be problematic in some

52. For example, in 1998, the federal enforcement capacity of the Yukon and Pacific region was reduced by more than one third. And in 1997, the job of public pest-inspectors was eliminated by the Ontario government.

53. One of the examples provided by the 1998 report of the Standing Committee on Environment and Sustainable Development, is that of a firm in Quebec, along with two individuals, who had been charged with 15 counts of polluting the St. Lawrence River contrary to provisions of the Fisheries Act. However, as the firm was acting under authorisation given by the Quebec government, it could not be prosecuted. 
cases. ${ }^{54}$ Examples include the Canada-Quebec agreement on federal pulp and paper mill regulations, where the numerous discharges in excess of the regulated standards in 1996 were not prosecuted.

56. In general, monitoring of toxic releases and pesticides is also insufficient. The National Pollutant Release Inventory - which exists also in other OECD countries such as the United States and Japan - is a very good information source that every Canadian can consult, and which should encourage enterprises to strive for a "clean" image in the eyes of the public. In Canada, however, its scope and coverage are limited. ${ }^{55}$ ARET also provides information, but data are inconsistent, incomplete and unverified. Finally, data on pesticide sales are missing (a regulation requiring registrants to submit sales data is anticipated by 2001). This makes it difficult to establish clear objectives and policy targets.

57. Recently, the federal government has acted to remedy these problems. First, the new Canadian Environmental Protection Act (proclaimed in April 2000) adopts a tougher stance on toxic substances. The 1999 budget provided C $\$ 42$ million over three years for the examination of some 23000 substances to determine their toxicity; the most dangerous will be eliminated, and deadlines have been adopted for taking action to manage effectively the others causing pollution. In addition, the powers of enforcement officers have been substantially expanded. Specific funding was also reserved for the implementation of the new CEPA (C\$ 72 million over five years) and for enforcement (C\$22 million over three years). ${ }^{56}$ To some extent, the Canada-Wide Standards initiative may also be a step in the right direction, as it provides clear guidelines to the various governments, but it concerns only six toxic substances. ${ }^{57}$

\subsubsection{Towards a $\mathrm{NO}_{x}-\mathrm{SO}_{2}$ trading scheme in Ontario}

58. Acid rain and smog are largely transboundary environmental problems in Canada and concern mostly the eastern provinces. ${ }^{58}$ Policy instruments used to date to reduce sulphur dioxide $\left(\mathrm{SO}_{2}\right)$ and nitrogen oxide $\left(\mathrm{NO}_{\mathrm{x}}\right)$ emissions have been mostly command-and-control and voluntary measures. ${ }^{59}$ Recently, however, the Ontario government has announced its intention to establish a trading scheme for $\mathrm{SO}_{2}$ and $\mathrm{NO}_{\mathrm{x}}$ emissions from the electricity sector, in the perspective of the opening-up of the electricity market at the end of this year. Such a scheme has already been in place for sulphur dioxide in the United States since 1995 (see OECD, 2000c). It has proved quite successful in reducing emissions in a

54. Seven federal-provincial agreements have been negotiated in relation to the CEPA and the provisions of the Fisheries Act relating to toxic substances, which have the advantage of providing the industry with a "single window". Matters covered by these agreements include research, training, monitoring, inspections and investigations. As a rule, however, both parties retain the authority to act under their respective legislation.

55. It includes only 10 of the 25 substances listed as top priority in the CEPA and covers only large companies

56. The first package was announced in September 1999 and the second in the 2000 budget. After the initial three years, incremental annual enforcement funding will continue at C\$9 million.

57. The Canada Wide Standards sub-agreement, signed in January 1998, aims at developing and attaining standards for substances that have general significance across the country and present significant human health or ecosystem risk. For more information, see www.mbnet.mb.ca/ccme.

58. Smog, or high concentration of tropospheric ozone, is also a problem in the Vancouver area, where a substantial share of emissions comes from the Seattle area.

59. Canada has succeeded in meeting its domestic, bilateral and international reduction targets for sulphur dioxide and nitrogen oxide. Targets (national or concerning only the seven eastern provinces) for $\mathrm{SO}_{2}$ were set in the 1985 Eastern Canada Acid Rain Program, in the 1991 Air Quality Accord with the United States, and in the two sulphur protocols of the UN-ECE Convention on Long-Range Transboundary Air Pollution (CLRTAP). Targets for NOx were set in the UN-ECE CLRTAP Sofia protocol and in the 1991 NOx/VOCs Management Plan ( $c f$. OECD, 1995). 
cost-effective way, and one for nitrogen oxide emissions has also been recently established in some parts of the United States.

59. Declining caps on $\mathrm{SO}_{2}$ and $\mathrm{NO}_{\mathrm{x}}$ emissions from the electricity sector have been in place in Ontario since 1986. The proposed scheme would reduce the current cap by 10 per cent for sulphur dioxide and 5 per cent for nitrogen oxide for the year 2001, which is relatively little compared with the reductions envisaged by the Acidifying Emissions Task Group in $1997 .^{60}$ The scheme would allow the utilities concerned to engage in buying and selling emissions credits with other entities sharing the same airshed as Ontario, provided they meet certain criteria. ${ }^{61}$ The value of distant emissions would probably be discounted to reflect their smaller environmental impact. The plan is to extend the scheme to cover the other major (non-electricity) emitters in Ontario in 2003. In addition to the cap-and-trade scheme, the Ontario government plans to introduce emissions standards per unit of electricity produced and imported equivalent to those in effect in the United States and has announced that it will modify its regulations accordingly when new US Environmental Protection Agency standards are implemented.

60. Setting up such a scheme would certainly enhance the cost-effectiveness of air pollution policy. Given the transboundary nature of the environmental problems, it would also be sensible to aim towards regional trading including other provinces concerned, in particular Quebec (where 50 per cent of the acid rain and 60 per cent of the smog come from Ontario and the United States). ${ }^{62}$ This would eliminate the need for introducing emission standards on top of the cap, which are meant to ensure that electricity imported is produced with the same type of standards as in Ontario. Given the local nature of the environmental problem, this makes sense only for electricity imported from firms producing in the same airshed. If they were also participating in the cap-and-trade scheme, standards and the possibility of "over-determination" could be eliminated.

61. In any case, it is important that the coverage of the scheme be extended to industrial emitters other than electricity, as they make up more than two-thirds of $\mathrm{SO}_{2}$ emissions and about a quarter of $\mathrm{NO}_{\mathrm{x}}$ emissions in Canada (in contrast to the United States, where the electricity sector is the major point source emitter). Another issue raised by this project is whether the objectives announced will be compatible with those that are currently negotiated nationally under the frame-work of the Canada-Wide Acid Rain Strategy and in that of the Canada-US agreement on ground-level ozone; both are expected to be completed late in 2000.

62. The scheme also raises interesting regulatory challenges. Up to now, there has been no regulatory agreement with the US authorities. Since 1995, a pilot trading scheme for $\mathrm{NO}_{\mathrm{x}}$ and $\mathrm{SO}_{2}$ emissions (PERT) has existed in Ontario, which allows transactions between Canadian and US companies. A transaction in which a US firm from Connecticut bought a $\mathrm{NO}_{\mathrm{x}}$ credit from a Canadian firm has been accepted by the US state authority as a "penalty" payment. At this stage, it remains a case-by-case approach, whereby regulatory authorities can make their own decisions. It is expected that the criteria in footnote 61 above will be the basis for the trading scheme being developed. The current approach is probably a necessary first step before reaching a bilateral regulatory agreement that would allow a more efficient functioning of the

60. The multi-stakeholder Acidifying Emissions Task Group concluded in 1997 that sulphur dioxide emissions should be reduced by 75 per cent below their 1997 cap (actual emissions were already about 25 per cent below their cap at that time), to reach the critical load - the deposition level that will not cause any harm to the eco-system. In fact, the reductions already achieved have had a smaller effect than expected on the eco-system.

61. Emission reduction credits created by sources outside the capped entities should be: 1) real; 2) quantifiable; 3) surplus, that is not otherwise required by current regulations or voluntary obligations; 4) verifiable; and 5) unique.

62. Emissions could be valued with a distance-related discount factor according to the damage they cause. 
market, with less official intervention. Ultimately, it seems reasonable to suggest that, as the airshed is largely transboundary in nature, the trading schemes should be integrated.

\subsection{Climate change}

63. The issue of climate change is gaining in importance on the environmental agenda in Canada. Canadian emission intensities of carbon dioxide are high by international standards, both per capita and per unit of GDP, especially when compared with western European countries (Figure 7). Under the terms of the as yet unratified Kyoto Protocol, Canada is committed to bringing its overall emissions of greenhouse gases (GHGs) - adjusted for possible permit trading - down to 6 per cent below their 1990 level on average between 2008 and 2012. This is a very challenging objective, since carbon dioxide emissions in 1997 were already 13 per cent higher than in 1990 and official projections published in December 1999 suggest that under current policies GHG emissions in 2010 would be some 27 per cent above their 1990 level.

64. If Canada was to meet the Kyoto target exclusively with domestic abatement measures, simulations from a number of models provide a cost estimate, in terms of GDP foregone in 2010, ranging from 1 to 2.3 per cent (Table 2). If an international market for emission permits is established and Canada purchases permits from the so-called Annex B countries ${ }^{63}$ who have lower abatement costs, the estimated GDP loss in 2010 would be reduced, ranging between 0.2 and 0.7 per cent. ${ }^{64}$ The costs could be cut even further if trade in greenhouse gas permits were to include developing countries, as strongly supported by the United States. ${ }^{65}$

63. Annex B to the Protocol lists the countries accepting emissions targets, that is OECD countries with the exception of Korea, Mexico, and Turkey, plus Russia and a number of economies in transition.

64. Canada signed the Kyoto Protocol on the understanding that it would have access to a number of "flexibility mechanisms", such as joint mitigation projects with other developed as well as developing countries, international emissions trading and soil sequestration ("sink" activities) in order to achieve its target.

65. The estimates for the price of permit per tonne of carbon provided by GREEN, the only among Annex B countries and $\$ 10$ to $\$ 20$ in the unlikely event that all developing countries were to participate. GREEN does not provide estimates for Canada of GDP losses and permit prices with no trade, as it is a sub-part of one of the regions considered by the model. In this latter case, the corresponding increase in the price of gasoline would be about 2 cents per litre (around 3 per cent of the current price in Ontario). If trading occurs among Annex B countries only, the increase in the price of gasoline would range between 6 and 10 cents (i.e. about 9 to 15 per cent of current Ontario price). 
Figure 7. Carbon dioxide emission intensities, 1997
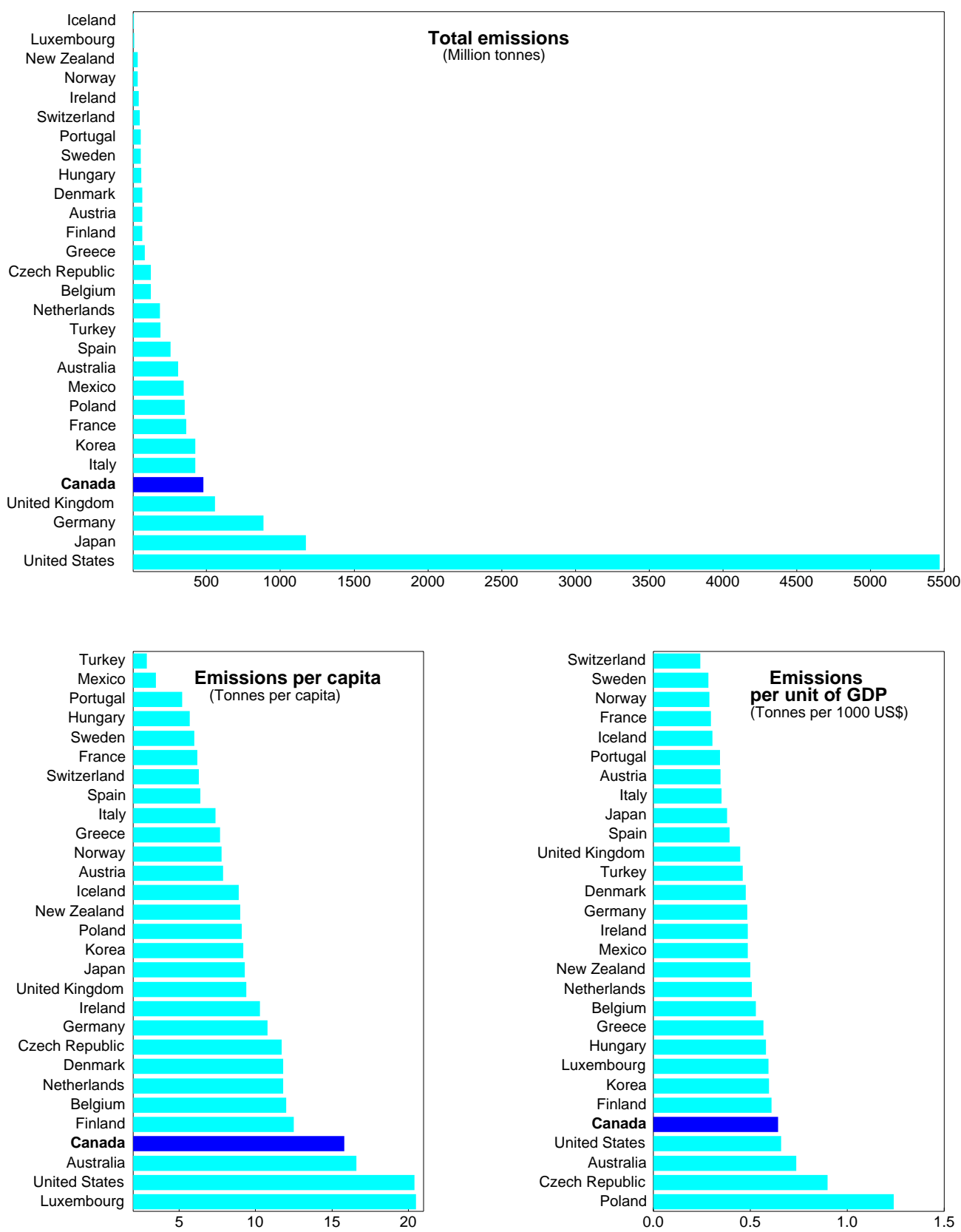

Source: OECD. 
Table 2. Economic costs of implementing the Kyoto Protocol

\begin{tabular}{|c|c|c|c|c|}
\hline \multirow[b]{2}{*}{ Model } & \multicolumn{2}{|c|}{$\begin{array}{l}\text { Price of emission permit, } \\
\text { US } \$ \text { per tonne of carbon }\end{array}$} & \multicolumn{2}{|c|}{$\begin{array}{l}\text { GDP foregone in } 2010 \\
\text { (per cent) }\end{array}$} \\
\hline & Domestic abatement & Annex B trading & Domestic abatement & Annex $B$ trading \\
\hline \multicolumn{5}{|c|}{1995 US\$ } \\
\hline MS-MRT $T^{1,2}$ & 347 & 69 & 2 & 0.7 \\
\hline $\begin{array}{l}\text { GTEM1 }^{1} \\
\text { GTEM2 }^{2}\end{array}$ & $\begin{array}{l}835 \\
378\end{array}$ & 87 & $\begin{array}{l}2.3 \\
1\end{array}$ & $\begin{array}{l}0.3 \\
0.2\end{array}$ \\
\hline
\end{tabular}

1. Carbon dioxide emissions only.

2. Carbon dioxide, methane and nitrous oxide emissions.

3. Figures were converted from Canadian dollars.

Source: Charles River Associates (1999), Tulpulé et al. (1998) and ABARE (1999).

65. Even with a substantial amount of emissions trading, meeting the Kyoto target will require a significant decline in fossil-fuel use. The carbon dioxide intensity of GDP has gradually declined since the start of the 1970s, but $\mathrm{CO}_{2}$ emission intensity per capita has not shown any such trend since 1983 and has even been increasing slightly since 1992 (Figure 8). There is some scope for extending the share of energy produced by non-emitting sources, but it is limited, as 75 per cent of electricity is currently generated from non-fossil-fuel sources (OECD, 2000a) ${ }^{66}$ Compared with other OECD countries, an important part of total GHG emissions comes from energy-intensive industrial activities based on natural resources. Emissions from the transport sector, which show the largest projected increase over the next decade, could be curbed only by considerable improvements in fuel economy or traffic reductions.

66. One important aspect of dealing with this problem in Canada rests with the structure of the federation, which allocates jurisdiction over many activities that affect climate change to the provinces and territories. In addition, there are differences in the regional distribution of the costs of meeting the Kyoto targets, which makes it even more difficult for the federal government to reach an agreement with the provinces on ratification and implementation. Being a fossil-fuel producer, Canada will be affected in two ways by the implementation of the Kyoto Protocol: first, reducing its emissions of GHGs would raise the cost of domestic production of energy-using output; and second, the reduction in consumption of fossil fuels abroad would reduce the demand for and prices of Canadian oil and possibly gas. Resource endowments and hence the structure of energy demand and supply are quite differentiated across regions, with fossil-fuel production mostly concentrated in Alberta, and of major importance to that province, nuclear production concentrated in Ontario, and hydro-electric production important in a number of provinces, in particular Quebec. ${ }^{67}$ Fossil-fuel-producing provinces will thus bear cost than the others. ${ }^{68}$

66. Regarding hydropower production, there are not many sites left, and opposition to the construction of new dams for environmental reasons has been mounting over the last decade.

67. Compared with a national average of about 23 tonnes of GHG emissions per person, Alberta produces about 71 tonnes of GHG emissions per person, Saskatchewan 59, New Brunswick 25, Nova Scotia 21, Ontario 17, Newfoundland 16, British Columbia 14, and Quebec and Manitoba 12 (IEA, 2000)

68. The extent of the cost to fossil fuel-producing provinces very much depends on the ease with which natural gas can displace coal in the US electricity sector. As for provinces exporting, non-fossil-based electricity, they will partly benefit from Kyoto implementation, as this will increase the export price. 
Figure 8. Evolution of carbon dioxide emissions intensities

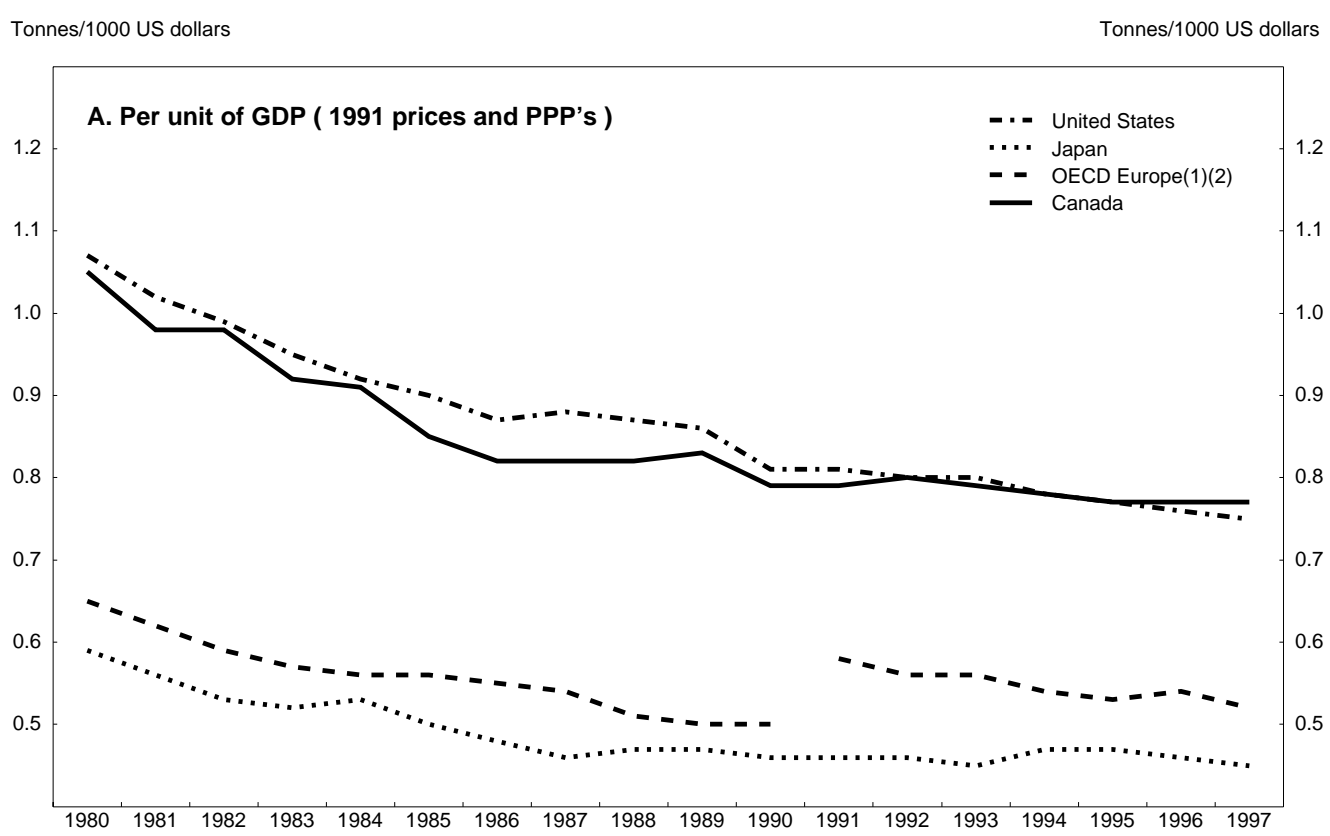

Tonnes/1000 US dollars

Tonnes/1000 US dollars

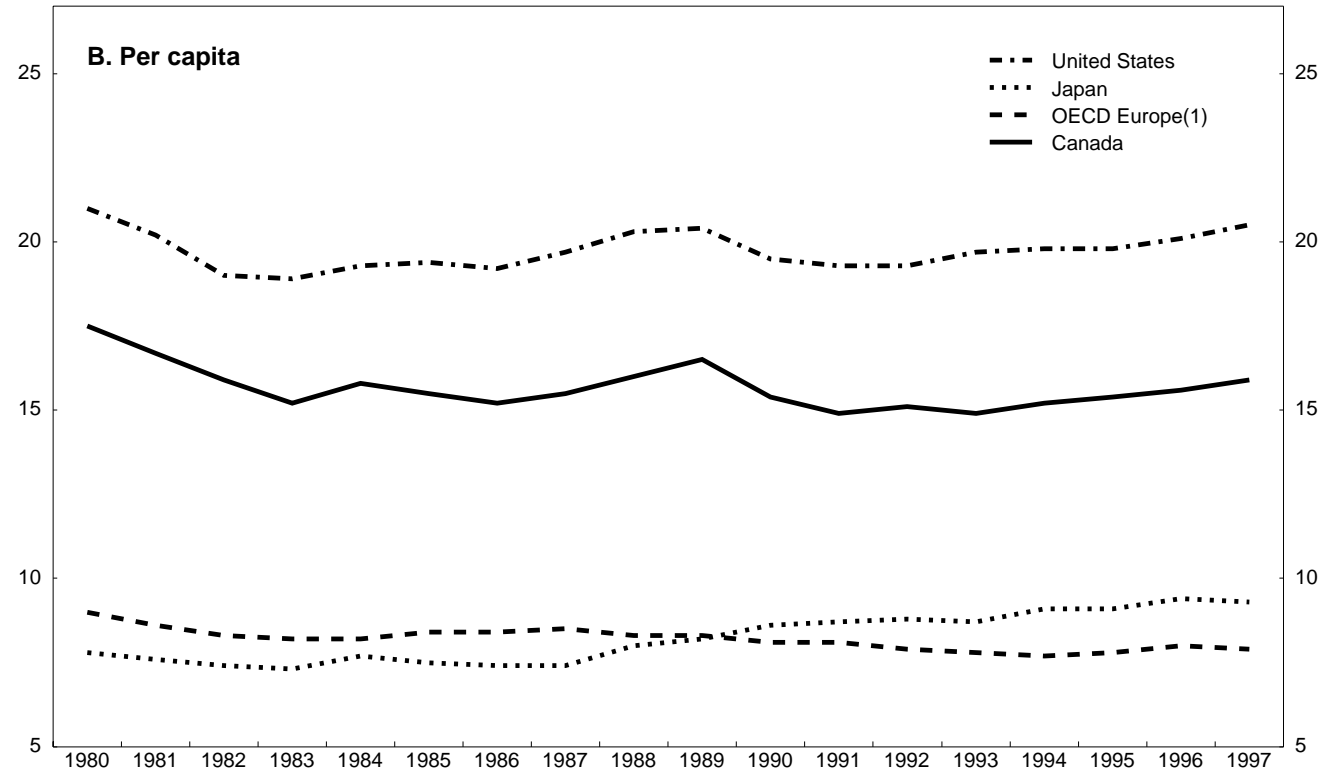

1. Excluding Czech Republic, Hungary and Poland.

2. Including West Germany until 1990 and total Germany afterwards.

Source: IEA. 
67. The Canadian governments have not finalised their climate change strategy yet. The comprehensive but lengthy consultation process launched in 1998 with 16 "issues tables" looking at costs and benefits of mitigation options in various areas (including electricity, forests, tradable permits) is expected to lead to a final report to the joint ministers of energy and environment at the end of this year. Up to now, a number of measures have been taken in various domains, many of which are voluntary initiatives and government spending programmes. ${ }^{69}$ Natural Resources Canada estimates that policies in place will lead to a reduction in GHG emissions of 8 per cent by 2010: with no measures, GHG emissions would be expected to be 37 per cent above their 1990 level in 2010, instead of 27 per cent. ${ }^{70}$

68. In the transport sector, fuel economy has been dealt with mainly through average consumption standards for new cars, set in a voluntary agreement with the automobile industry, equivalent to the US CAFE standards. ${ }^{71}$ Other instruments include a federal excise tax on high energy-consuming motor vehicles and a graduated sales tax according to fuel consumption in Ontario. The effectiveness of these instruments has been limited, however, as essentially no improvement in average fuel efficiency of new light vehicles has occurred since 1982 (Figure 9). In part, this reflects an increase in the size of the average vehicle, with sales of mini-vans, sport utility vehicles and light trucks growing faster than those of automobiles.

69. If GHG emissions from the transport sector are to be contained, a substantial increase in fuel prices will be required. ${ }^{72}$ Given the direct link between fuel use and such emissions, an increase in fuel prices is a perfectly targeted instrument, and such price signals would be needed to induce the necessary structural change (that is more rapid technological change favouring vehicles with better fuel economy and a shift towards transport modes producing fewer emissions). Voluntary agreements, regulations and subsidies favouring fuel efficiency may have some effect at the margin, but, as observed, they may also be offset by an increase in vehicle weight or in the number of passenger - or tonne-kilometres travelled.

69. Some regulatory measures were also used, such as energy efficiency standards for lighting (estimated to reduce greenhouse gas emissions by 5 megatonnes annually by 2000), household appliances and electric motors.

70. The 2000 budget provides about $\mathrm{C} \$ 625$ million in additional funds over the next five years for programmes related to climate change.

71. As far as average consumption standards are concerned, this makes sense in an integrated North American automobile market, as it minimises the costs of meeting those standards through economies of scale.

72. Trucking is a major source of greenhouse gas emissions, representing 27 per cent of the emissions from transport, of which they are the most rapidly growing component. 
Figure 9. Canadian motor vehicle fuel efficiency Litres per 100 kilometres

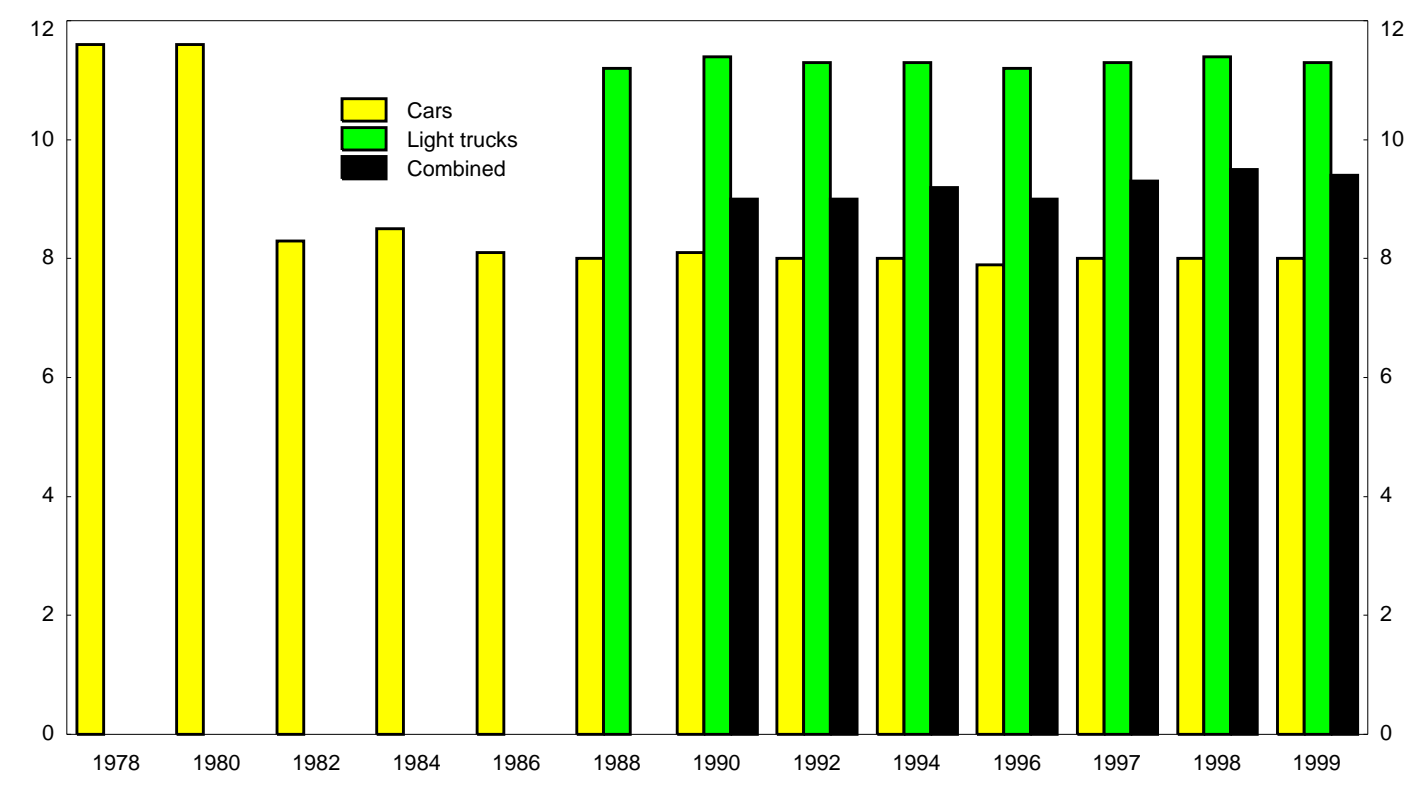

Source: Transport Canada,1999.

70. The current low level of fuel prices provides little incentive to reduce fuel consumption. Taxes on fuel are higher than in the United States, but significantly lower than in most other OECD countries (Figure 10). ${ }^{73}$ Although there is no recent quantitative study on cost recovery in the transport sector, it is generally recognised that the costs of externalities associated with road traffic exceed revenues from fuel taxes in Canada. A study sponsored by the Ontario Roundtable on the Environment and Sustainable Development estimated the total external costs (including those resulting from climate change) of car and truck use to be around C $\$ 12$ billion in 1994, compared with C $\$ 2$ billion for other transport modes (IBI Group and Boon, Jones and Associates Inc., 1994). ${ }^{74}$ Correspondingly, the highest increase in user charges required in order to cover external costs was found to be for urban passenger cars. Since that date, price incentives have probably been twisted further towards road transport. With shrinking public-sector budgets, subsidies to urban public transit have been reduced over the 1990s, substantially increasing its

73. The federal tax rate is 10 cents per litre of gasoline and 4 cents per litre of diesel. Provincial tax rates range from 9 cents for both diesel and gasoline in Alberta to 16.5 cents in Newfoundland.

74. The environmental costs are estimated based on estimates of the costs of emissions of various gases per tonne or passenger-kilometre. 
Figure 10. Petrol taxes in international comparison Total taxes levied in 1998, US\$ per litre

\section{A. Unleaded premium (95 RON)}

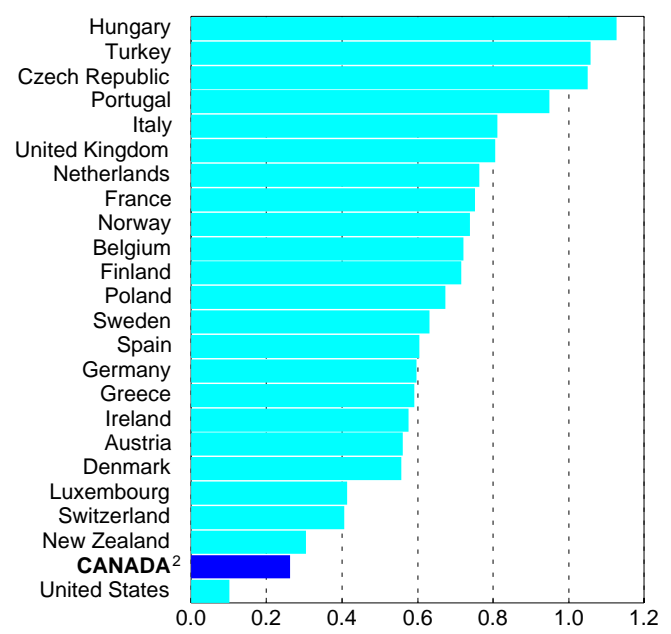

\section{B. Diesel fuel (for non-commercial use)}

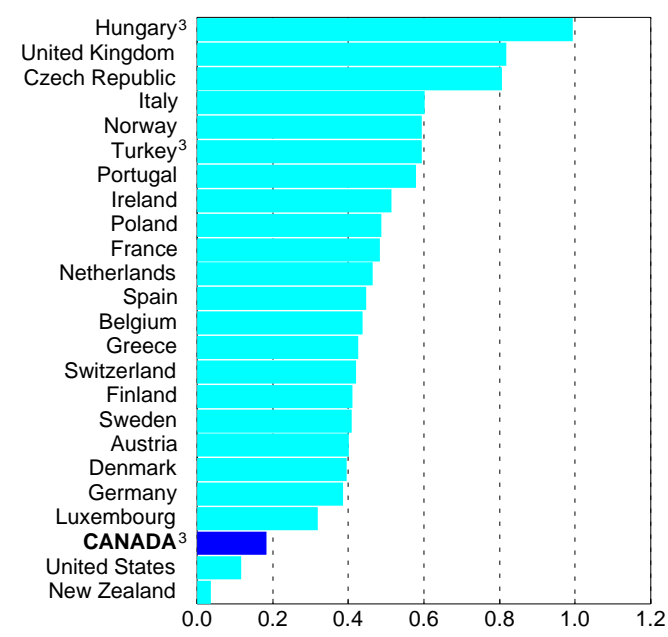

1. Using current purchasing power parities.

2. $98 \mathrm{RON}$.

3. For commercial use.

Source: IEA, Energy Prices and Taxes and OECD, Main Economic Indicators.

price ${ }^{75}$ while road maintenance and construction have not faced the same decline in funding levels as have other transport modes (Resource Futures International, 1996).

71. As in the United States, the resistance to an increase in fuel price is intense, as illustrated by the fact that the preferred options retained by the issue table on transportation are mostly non-price measures. ${ }^{76}$ There are fears that, given the proximity with the United States, a unilateral increase in fuel prices would both reduce the competitiveness of Canadian firms and be ineffective due to cross-border fuel purchases by Canadians. While it is true that increasing the fuel price will affect the competitiveness of firms relying heavily on road transportation, this is part of the structural change that the commitment to GHG emission reduction implies. Trying to reduce emissions without such a structural change and without using direct

75. The price of urban public transit increased by 69 per cent in the decade to 1999 , a 36 per cent rise in real terms.

76. See the option paper of the issue table on transportation on the website of the National Climate Change Process (http: Ilwww.nccp.ca). The cost-effectiveness of an increase in fuel taxes is recognised, but the magnitude of the increase required is considered incompatible with "the value that Canadians place on the convenience, necessity and pleasure of transportation". 
price signals would damage the overall competitiveness of the Canadian economy even more. ${ }^{77}$ As for the cross-border "leakage" argument, it is difficult to estimate the scale of that possible leakage ${ }^{78}$ but in any case, retail fuel purchases in the United States would count towards US GHG emissions, not Canadian ones. The problem is more one of tax revenue losses for the federal government rather than ineffectiveness of the measure. ${ }^{79}$

72. The sharp increase in road traffic is also very much related to the phenomenon of urban sprawl. As in the United States, the car has made it possible for an increasing share of the population to live in low-density suburbs. Urban land development policies have encouraged this trend - with, for example, zoning restrictions limiting residential densities. ${ }^{80}$ The current structures of property tax, based on market value assessment, and of development cost charges (that is the mechanisms for raising revenues to pay for new infrastructure) also play a role ${ }^{81}$. Automobile-dependent urban sprawl, in turn, is also self-sustaining, as traditional public transport systems are rarely cost-effective in these low-density and widely dispersed areas. ${ }^{82}$ As in the United States, urban sprawl and low prices for fuels tend to be mutually reinforcing $(\mathrm{OECD}, 2000 c)$. On the one hand, car-dependent residents resist proposals to increase the cost of driving, and on the other cheap fuel favours the continuing development of low-density housing. However, higher fuel prices may be more effective in reducing emissions from transport than subsidies for public transport.

73. In the industrial sector, most federal and provincial governments' initiatives taken up to now to mitigate greenhouse gas emissions rely on voluntary measures. The Voluntary Challenge and Registry (VCR), initiated in 1995, registers voluntary commitments to reduce GHG emissions. Despite very wide coverage, the effectiveness of this initiative has been widely questioned, as it provides few incentives and has low accountability and verifiability. According to the IEA (2000), it is difficult to determine whether a particular action would have taken place in its absence. At the provincial level, some initiatives seem to be successful in reducing emissions in a cost-effective way, such as Alberta's efforts to reduce those from oil and gas flaring.

74. Voluntary programmes fostering energy efficiency are also an important element of the current Canadian measures for climate change mitigation. ${ }^{83}$ As in the case of VCR, though, the agreed rate of improvement does not appear to be a large step beyond autonomous energy efficiency improvement

77. The competitiveness issue has been dealt with at length in previous OECD Economic Surveys' chapters on the same subject. For example, see OECD (1999d), OECD (2000c) and OECD (2000d).

78. Just as significantly lower sales tax in the United States does not result in Canadians living in the border area doing all their shopping in the United States, it would probably not do so in the case of fuel.

79. There are also probably ways to partly address the problem, by for example introducing a graduated tax based on the distance from the border, provided that the administrative costs associated with such a tax do not offset the "retained" tax receipts ( $c f$. OECD, 2000c).

80. Municipalities are increasingly aware of these problems, and some, such as Greater Vancouver, are launching initiatives to reverse this trend and reduce associated emissions of GHGs and other air pollutants. However, the effective implementation of changes in land use faces strong resistance from people that have already invested (in houses or commercial buildings), and creates a number of transition problems.

81. See Municipalities Table Options Paper, 1999 (at http://www.nccp.ca/html/tables/pdf/options/MT_OR-121999.pdf).

82. As a matter of fact, public transport services require subsidies even in densely populated areas.

83. Programmes such as Energy Innovators and the Canadian Industry Program for Energy Conservation (CIPEC) set sectional targets and get member companies to comply. CIPEC's 21 task forces representing a total of 3000 companies, achieved an overall decrease in energy intensity of 0.9 per cent per year between 1990 and 1997, while their value added increased by 2.3 per cent annually over the same period. 
IEA (2000). More generally, there are some limits to cost-effective reduction of GHG emissions through energy efficiency programmes. First, as discussed above for the transport sector, energy-efficiency improvement cannot be expected to result in equivalent decreases in energy intensity, because if prices stay the same, relative cost effects will increase energy demand ${ }^{84}$ Second, energy intensity as such is not what matters in the case of climate change, and policies focused on energy use rather than GHG emissions per se run the risk of orienting incentives in a direction that is not cost-effective.

75. All this points to the importance of relying on market and price mechanisms to achieve a cost-effective reduction in GHGs. "Win-win" opportunities, that is measures reducing emissions without costs (or at least without significant costs) are probably scarce, therefore limiting the scope of mitigation achievable with voluntary initiatives. The possible contribution of forestry activities to Canadian climate change mitigation policy is also very uncertain, as depending on the out-come of ongoing international negotiation over the definitions of afforestation, reforestation and deforestation, Canadian forestry may be considered a substantial source of GHG emissions or a sink (a source of GHG absorption) ${ }^{85}$

76. The possibility of setting up a domestic market for GHG emission quotas is one of the options being considered in the consultation process. This option has also been studied by various stakeholders in the framework of the National Round Table on the Economy and the Environment, which concluded that it would be a cost-effective way of meeting the target (National Round Table on the Environment and the Economy, 1999). Disagreement remained, though, on the coverage of the scheme and the extent to which other regulatory and voluntary instruments should be used complementarily. In fact, some voluntary credit trading has already taken place in Canada, allowing firms to gain some experience in trading, which, compared with the usual regulatory/technical instruments, involves relatively new skills. Several emission reduction projects have been accepted for registration under the umbrella of the Greenhouse Gas Emission Reduction Trading Pilot (GERT), launched in June 1998. ${ }^{86}$ In addition, two Canadian firms have been involved in the purchase of larger emission credits (or options) from American companies or organisations. ${ }^{87}$

77. Overall, Canadian greenhouse gas emissions are likely to exceed the Kyoto target for the period 2008-12 substantially, and Canada will thus have to use the Protocol's flexibility mechanisms. In this perspective, though, it would be important to get an agreement on a domestic permit scheme, which could be linked to international permit trading, with a coverage as broad as possible. Keeping some sectors out of the scheme, like transportation or any other energy-intensive industry, would end up increasing the overall cost of reducing emissions. Distributional effects, on the other hand, could initially be handled with the rules retained to allocate the permits. Grandfathering part of the emission quotas may be an option to make the scheme more acceptable to industry. Given that the costs of meeting the Kyoto target will be unequally

84. For a discussion of what they call the "rebound" effect, see Birol and Keppler (2000).

85. See Sinks Table Option Paper, 1999 (at http://www.nccp.ca/html/tables/pdf/options/Sinks_OR-Sep-231999_en.pdf).

86. Three Canadian projects have been accepted as having met the criteria for registration under the GERT Pilot, and there six more projects currently being reviewed. One project is being registered in the GERT process as a trade matched project - one where there is both a buyer and seller of emission reductions: Ontario Power Generation Inc. purchasing almost 90000 tonnes of $\mathrm{CO}_{2}$ emission reductions that were expected to be generated during 1999 by the Star Lake Partnership. GHG emission reductions are being created because the hydroelectrically-generated power at Star Lake is displacing fossil fuel-based power currently generated on the Avalon Peninsula in Newfoundland.

87. Ontario Power Generation has purchased credits of 2.5 million tonnes of carbon dioxide from Zahren Alternative Power, a small American firm that captures methane from landfills. A coalition of Canadian energy companies has also bought 3.3 million tonnes of carbon dioxide credits from Iowa farmers that are generating the credits from not tilling the soil. 
distributed among provinces, some kind of regional compensatory scheme may also be required to get an agreement with the provinces. ${ }^{88}$ It would be important, however, that it be completely independent of future emissions.

\section{Concluding remarks}

78. This paper has focused on a selected number of key natural resource and environment issues, with particular attention to how these interact with the wider policy-setting framework. General features of Canada's policies dealing with natural resource and the environment stand out. The main recommendations that emerge from this analysis are set out in Box 4.

79. The rich endowment of natural resources has led to policies favouring their development and use. Support has been important for activities based on non-renewable resources, such as oil and gas, and metals and minerals, mostly in the form of preferential tax treatment distorting investment incentives. Given that non-renewable-resource-based activities are generally intensive producers of GHGs and polluting substances, the overexploitation of such resources also has direct environmental consequences. Recently announced tax measures that will contribute to levelling the playing field are therefore to be welcomed.

80. In the same way, the implicit subsidisation of water supply lowers its price and leads to overuse. While the federal government has been endorsing the principle of "economic" pricing of water for some time, local governments, which are responsible for water management, are moving only slowly in this direction. Water availability has started to be a problem in some regions, in particular those with large irrigated areas, and in these cases current systems of water rights end up excluding other potential users. To improve allocative efficiency, plans to introduce the transferability of water rights have been announced. Resistance to such moves as well as to full cost pricing is high, in particular from those benefiting most from the current subsidies, but the benefits of correcting this unsustainable situation are substantial, and the authorities should therefore speed up their move towards "economic" pricing. This would be consistent with the recent decision to ban bulk water removal, preventing therefore bulk exports, which reveals a very high implicit valuation of water. In the longer-run, however, a carefully designed export licensing system would allow Canada to reap some benefits from its abundant water resource, while at the same time preventing harmful environmental effects.

88. The National Climate Change Process, the current federal government strategy, includes a requirement that "no region of the country should be asked to bear an unreasonable burden". 


\section{Box 4. Summary of conclusions and recommendations for reform}

\section{Objective setting and implementation}

- All levels of government need to work further on clarifying the objectives of their policies. This is particularly the case for fisheries and environmental policies. Designing mechanisms for decision-making when there are conflicting views among various departments (at the federal level, at the provincial level, among provinces, and between provinces and the federal government) and increasing transparency in decision-making - for example by making greater use of cost-benefit analysis and making it more frequently available to the public - would also improve cost-effectiveness of policy.

- To reduce the gap between objectives and achievements, a particular focus should be put on trying to find commitment devices for stakeholders. A number of specific changes would be useful in this regard:

- Increasing the quantity of environmental information made available to the public.

- Setting clear rules for actions (for example, to fix total allowable catches; to assess the reference level of emissions of firms participating in voluntary agreements and the actions to be taken in case of non-compliance with voluntary agreements or regulation).

- Making more extensive use of economic instruments. Compared to a fine, a tax or charge leaves much less room for discretion. Individual quotas formalise a commitment to a certain harvest level or emission target, and when transferable, those who own them all have an interest in effective enforcement as otherwise their value drops.

\section{Energy, minerals and metals}

- The preferential tax treatment of conventional resource sectors, such as oil and gas and minerals and metals, should be eliminated. The federal government has started moving in that direction in its 2000-01 budget, but the process should be accelerated. This would also help to meet environmental objectives, in particular the Kyoto commitment.

\section{Water use}

To allow more efficient water use, provincial and territorial governments should:

- Speed their move towards "economic pricing", by shifting the burden from taxpayers onto users and charging according to volume consumed. This requires increased use of water metering, which is currently relatively scarce. The current subsidies to irrigation water result in higher levels of agricultural production and thus increased level of pollution.

- In areas where availability of water has become a problem, make water rights transferable (provided it does not harm the ecosystem) to increase allocative efficiency.

- Maintaining a moratorium on bulk water removal may be justified in the short run to assess more precisely the associated economic and environmental costs and benefits. But in the longer run an exportlicensing regime may be designed that takes into account environmental concerns. 
ECO/WKP(2001)16

\section{Box 4. Summary of conclusions and recommendations for reform (cont.)}

\section{Atlantic fisheries}

- Progress has been made in managing the Atlantic fisheries. However, the sector is still overcapitalised and comprises too many fishers, and the incentives provided by economic and social policies conflict with the long-run sustainability of the sector:

- The share of fisheries managed through individual quotas has increased (to 50 per cent), but further extension should be considered. Increasing the transferability of quotas where none exists and removing restrictions on such transferability would be beneficial, as it would allow the reduction of excess capacity.

- A precautionary approach should be applied more strictly when setting total allowable catches for shellfish, as otherwise similar problems as for groundfish may arise. Rule-based management could be adopted for specific fisheries, in which scientific recommendations for total allowable catches have to be followed, as has been done for some fisheries in Iceland, for example.

- The current system for charging should be clarified. User charges should be consistently applied to the various individual fisheries, to allow for efficiency gains in the provision of services and reducing the incentives for oversize. To tax the high rents likely to result from transferable quotas, they should be auctioned or at least more systematically charged for.

- The effects of the reform of the employment insurance scheme seem to have been limited for the fishery sector. The regional differentiation of employment insurance inhibits mobility. In general, the support provided to fishers and fish-processing workers affected by the crisis should be designed so as not discourage seeking other employment possibilities.

- The federal government should consider increasing the generosity of the amounts proposed for license retirements as a measure to reduce the size of the sector.

\section{Pollution}

- Policies dealing with pollution should apply the polluter pays principle more systematically. In this regard:

- A mechanism for decision-making regarding the classification and evaluation of toxic substances should be created.

- There is scope for substantially increasing the use of economic instruments. Possible examples include: charges on toxic emissions, effluent or waste; water discharge permit trading; a tax on pesticides; and advance disposal fees for products containing toxic substances.

- The federal government should continue its efforts to provide provincial and territorial governments with information and tools (models, available cost-benefit analysis on similar subjects) to favour their use of economic instruments.

- The coverage of the National Pollution Release Inventory should be increased, as it provides a valuable information source both for the public and the authorities.

- Reliance on voluntary agreements has not been sufficient to achieve environmental objectives. When relied on, they should provide for accountability and verifiability and specify actions to be taken in case of non-compliance (that is they should be backed up by regulation or economic instruments). 
Box 4. Summary of conclusions and recommendations for reform (cont.)

- The project to set up a tradable scheme for $\mathrm{NOx}$ and $\mathrm{SO}_{2}$ emissions in the electricity sector in Ontario should be welcomed. However, for it to be cost-effective, it would be important to extend its coverage to emissions from other industries as well as to emissions from provinces sharing the same airshed. The aggregate cap put on emissions must be consistent with forthcoming objectives negotiated nationally under the framework of the Canada-Wide Acid Rain Strategy and in the framework of the Canada-US agreement on ground-level ozone.

\section{Climate change}

- In the field of climate change, the Canadian government has taken a rather high profile in international fora, but GHG emissions are still increasing strongly and more actions should be taken. Even if Canada is able to buy GHG emission quotas on an international market, it will have to take steps to accelerate the reduction in fossil-fuel consumption per unit of GDP. To this aim, it should:

- Implement an economic instrument with an emission base as large as possible in order to reduce the overall costs of emissions abatement. Voluntary agreements to reduce GHG emissions and improve energy efficiency have shown their inefficiency. A "cap-and-trade" scheme is probably the most appropriate approach.

- In the absence of a cap-and-trade scheme covering fuel-based emissions, increase the tax on fuel, as it will be more effective and less costly than average consumption standards to reduce emissions from transport.

81. What happened in the Atlantic groundfisheries provides an example of how public support provided in different forms, including through employment insurance and labour market policies, can contribute to the depletion and collapse of fish stocks, as it reinforces the already existing incentives for over-exploitation resulting from the common nature of the resource. Canada is not the only country that has faced such problems, and natural factors may also have been particularly unfavourable there, but the reaction to the reduction of the stock has been slow, illustrating the difficulty in trading off the short-term adjustment costs for fishing communities, with their distributional and regional implications, against the long-term sustainability of the activity. Not directly addressing the current distributional problems, however, will lead to more serious distributional problems in the future. Measures to tackle them should be clearly separated from those designed to improve resource management.

82. The support provided by governments for resource development may be linked with the use of a rather "co-operative" approach in environmental policy, in which standards are often closely negotiated with the industry, rather than being based on a consistent cost-benefit approach, and their enforcement is not systematic and also subject to negotiation. This is particularly the case for the provinces, as their role as promoters of natural resource development conflicts somewhat with their ability to impose the costs of environmental protection and resource conservation on the firms who are their agents. The political economy of environmental regulation, which imposes concentrated costs on the regulated sector in order to provide diffuse benefits to the public, always makes it difficult to implement a regulation and apply the polluter pays principle. In the Canadian case, though, this effect seems to be reinforced by governments' role in resource development, as well as by the constitutional ambiguity and overlapping jurisdictions with respect to environmental matters.

83. The federal government has taken a rather high profile on some issues, having announced important steps to be taken in the realm of toxic substances management policy, and being, for example, a strong proponent of international action on issues such as climate change and an active promoter of 
international agreements for fisheries management. Each federal department has developed strategies for sustainable development, and a unique and valuable function of Commissioner of the Environment and Sustainable Development has been created. Many consultation processes have been launched, such as, for example, the issue tables for climate change. However, as underlined by many observers and the Commissioner himself, actions have not always followed from these processes. Implementation problems also exist at the provincial level. Objectives and/or intermediate targets are not always clearly set in the various areas, for example fisheries and toxic substances management. While it is true that reconciling diverging views among the various departments and ministries concerned may be especially difficult in Canada, a rather loose federation with shared jurisdictions, it must be recognised that implementing no measures at all often implies environmental degradation (or resource depletion) to the detriment of current and future generations. Improving both the mechanisms for decision-making at each government level and the co-operation mechanisms between the two levels of government, in particular their accountability, would help in this respect.

84. The frequent recourse to voluntary agreements, partly as a result of reductions in funding of the government departments responsible, has not proved effective in dealing with the resource and environmental challenges, as shown by the management of toxic substances and in the policies to curb GHG emissions. Self-regulation faces the same limits as elsewhere. "No-cost" opportunities for pollution reduction are limited, and, by definition, self-regulation cannot be expected to correct for the external costs of pollution. In this respect, the project to introduce a tradable permit scheme for $\mathrm{NO}_{\mathrm{x}}$ and $\mathrm{SO}_{\mathrm{x}}$ emissions in Ontario should be pursued.

85. To put Canada on a more sustainable growth path, greater reliance on price signals is needed. Increasing the use of economic instruments will indeed prove necessary if Canada is to achieve significant cost-effective progress in terms of resource conservation, allocative efficiency and environmental performance. The benefits from greater recourse to economic instruments would be particularly welcome in a period in which competitive pressures are heightened and marginal costs of abatement are climbing. 


\section{REFERENCES}

Birol, F. and J. H. Keppler (2000),“Technology, Prices and Energy Efficiency”, STI Review No. 25, Special Issue on Sustain-able Development.

Brewer K. J. and A. Lemieux (1997), "Canada's Global Position in Mining”, Natural resource Canada, Ottawa (http://nrn1.nrcan.gc.ca:80/mms/efab/invest/metals/title.htm).

Department of Fisheries and Oceans (1999), Canada's Strategy for Fisheries Reform and Renewal, October.

Fisheries Resource Conservation Council (1997), A Groundfish Conservation Framework for Atlantic Canada, Report to the Minister of Fisheries and Oceans, FRCC 97.3, July.

Horbulyk, T.M, and L. J. Lo (1998), Welfare Gains from Potential Water Markets in Alberta, Canada", in K.W. Easter, M.W. Rosegrant and A. Dinar (eds), Markets for Water: Potential and Performance, Natural resource management and policy series, Kluwer.

Horbulyk, T. M. and L. J. Lo (1998), "Welfare Gains from Potential Water Markets in Alberta, Canada".

IBI Group and Boon, Jones and Associates Inc. (1995), Full costs Transportation and Cost-Based Pricing Strategies, November.

IEA (2000), Energy Policies of IEA Countries, Canada 2000 Review, Paris.

Kaufmann B. and G. Geen, (1997), "Cost recovery as a fisheries management tool", Marine-Resource-Economics, Vol. 12(1), pp. 57-66, Spring 1997.

Krarup, S. (1999), "Voluntary agreements in energy policy", mimeo.

National Round Table on the Environment and the Economy (1996), Water and Wastewater services in Canada, Ottawa.

Natural Resources Canada (1999), Summary of mining-related measures announced in 1998, http://nrn1.nrcan.gc.ca:80/mms/ efab/tmrd/budget_summary98.htm.

OECD (1995), Environment Performance Reviews, Canada, OECD, Paris.

OECD (1999a), Economic Survey of Canada, OECD, Paris.

OECD (1999b), Implementing Domestic Tradable Permits for Environmental Protection, OECD Proceedings, Paris.

OECD (1999c), Voluntary Approaches for Environmental Policy - An Assessment, Paris. 
OECD (1999d), Economic Survey of Finland, Paris.

OECD (1998), Towards Sustainable Development - Environmental Indicators, Paris.

OECD (2000a), Case Study of the Governance for Sustainable Development, Paris.

OECD (2000b), Economic Survey of Canada, Paris.

OECD (2000c), Economic Survey of the United States, Paris.

OECD (2000d), Economic Survey of Denmark, Paris.

Harrison, K. (1997), Passing the Buck - Federalism and Canadian Environmental Policy, UBC Press, Vancouver.

Hessing, M. and M. Howlett (1997), Canadian Natural Resource and Environmental Policy - Political Economy and Public Policy, UBC Press, Vancouver.

Munro, G. R. and S. McCorquodale (1981), "The Northern Cod Fishery of Newfoundland", in Public Regulation of Commercial Fisheries in Canada, Case Study No. 3, Ottawa: Economic Council of Canada.

Pollution Probe (1999), Towards Credible and Effective Environmental Voluntary Initiatives: Lessons Learned, June, Toronto.

Report of the Auditor General of Canada (1999), "Fisheries and oceans - managing Atlantic shellfish in a sustainable manner", Ch. 4, April.

Report of the Commissioner of the Environment and Sustainable Development (1999).

Report of the Commissioner of the Environment and Sustainable Development (2000).

Renzetti (1999), "Municipal water supply and sewage treatment: costs, prices and distortions", Canadian Journal of Economics, Revue canadienne d'economique, Vol. 32, No. 3.

Renzetti, S. and D. Dupont (1999), "An Assessment of the Impact of Charging for Provincial Water Use Permits", Canadian Public Policy - Analyse de Politiques, Vol. XXV, No. 3.

Resources Future International (1996), Transportation grants and subsidies: their environmental implications, Transport Canada Discussion Paper 5, September.

Schrank, W. E. (1996), "Origins of Atlantic Canada Fishing Crisis”, in D.V. Gordon and G.R. Munro (eds), Fisheries and Uncertainty - A Precautionary Approach to Resource Management, University of Calgary Press.

Smith, R. T. (1994), "The Economic Structure of Contracts for International Water Trades", in T.L. Anderson (ed.), Continental Water Marketing, Pacific Research Institute for Public Policy, San Francisco.

Standing Committee on Environment and Sustainable Development (1998), "Enforcing Canada's pollution laws: The public interest must come first!", Third report, May. 
Van Kooten, G. C. and A. Scott (1995), "Constitutional crisis, the economics of environment, and resource development in Canada", Canadian Public Policy - Analyse de politiques, XXI:233-249.

Veeman, T. S. and M. M. Veeman, with W.L. Adamovicz, S. Royer, B. Viney, R. Freeman and J. Baggs (1997), "Conserving water in irrigated agriculture: The economics and valuation of water rights", Project Report No. 97-01, Department of Rural Economy, University of Alberta.

World Economic Forum (2000), Pilot Environmental Sustainability Index, An Initiative of the Global Leaders for Tomorrow Environment Task Force, Annual meeting 2000, Davos. 
ECO/WKP(2001)16

\section{ANNEX I. INSTITUTIONS AND POLICIES IN THE AREA OF RESOURCES AND THE ENVIRONMENT IN HISTORICAL PERSPECTIVE}

\section{Institutional responsibilities $^{1}$}

1. Canada's institutional set-up has played a major role in the definition of resource and environmental policies, as well as their evolution. It is a federal state in which each of the ten provinces and three territories has considerable autonomy, much more than in the United States, for example. The Canadian constitution gives responsibility to provincial and territorial institutions for everything that is not explicitly stated as federal. This gives them a major role in the policy area under consideration.

2. Provinces are the key players in resource policy. They own their natural resources such as coal, oil and gas, as well as the majority of the forests. ${ }^{2}$ Moreover, they have the authority to legislate with respect to both publicly and privately owned resources within the province. The major exception to this rule concerns fisheries and migratory birds which, as a common property transcending provincial boundaries, fall under federal jurisdiction. ${ }^{3}$ The federal government also exercises varying degrees of control over other resources through its sectoral power over agriculture and navigation, and through more general constitutional provisions - spending and taxing power, criminal law, interprovincial and international trade, and emergency powers falling under the "Peace, order and good government" clause of the Constitution. It has also jurisdiction over its own properties.

3. As the environment is not explicitly addressed in the Constitution, the division of powers regarding Canadian environmental policy between the various levels of government also flows to a great extent from jurisdiction over resources. Environmental management is thus shared between the various levels of government. A responsibility to protect fish provides the federal government with the opportunity to regulate water quality, in particular in coastal areas; federal authorities are charged with regulating pesticides in agriculture; navigation and shipping authority grants them a veto power over all developments that can affect the flow of water (such as dams and bridges on navigable waters); they are responsible for environmental protection of Aboriginal territories; and they undertake environmental monitoring and research. Apart from these sectoral responsibilities, federal regulatory activity in the environmental field is limited to international and interprovincial pollution, federal land developments and controlling toxic substances. Provinces, on the other hand, are responsible for pollution control on their territories. Municipalities are generally responsible for land-use functions such as the provision of water and sewerage services, zoning and the layout of roads. Together, the provinces and local governments (which are under their tutelage) are responsible for a large part of Canada's environmental regulation.

1. The discussion of this section draws heavily on Hessing and Howlett (1997), Harrison (1996), OECD (1995) and Van Kooten and Scott (1995).

2. This is the case not only for resources under provincial land, but also under private land.

3. In the case of inland fisheries not crossing provincial boundaries, though, the rights of the provinces have been upheld by the courts (Hessing and Howlett, 1997). 


\section{$\mathrm{ECO} / \mathrm{WKP}(2001) 16$}

\section{Development of policies}

4. Royalties from the sale or lease of natural resources were (and still are in some cases) a very important source of revenues for the provinces, which have therefore strongly encouraged resource development. Progressively, though, the focus has shifted towards long-term resource conservation, and they have created institutions and established regulations and instruments for that purpose (such as longterm tenure in forest management). Initially, the role of the federal government was restricted to administering its own properties and trying to promote resource conservation through persuasion. ${ }^{4}$ After the second world war, however, in its reconstruction efforts, the federal government started to rely on its spending power to support resource development. With the Canada Forestry Act (1949), for example, the federal government entered into shared-cost conditional grant programmes with the provincial governments. It also intervened more directly, notably in the energy sector. To support the development of oil production in western Canada, in the 1960s, the federal government prevented consumers west of the Ottawa River Valley from purchasing oil from foreign sources, thereby increasing prices significantly compared to the world market. Conversely, after the oil shock in 1973 and until the liberalisation of the energy market in the 1980s, the federal government froze the price of oil and subsidised oil imports in eastern Canada through taxes on exports and oil companies, heightening the tensions between the western provinces and the federal government. The latter also subsidised exploration outside the producing provinces. More generally, the federal government also provided grants to the resource sector through various regional development programmes.

5. In the environmental field, the main mechanisms to regulate pollution were established in the early 1970s, when a number of incidents both outside and inside Canada heightened public concern about environmental problems and brought them onto the policy agenda. Regulatory statutes for environmental licensing were passed in a number of provinces and bodies established to administer them. The federal government also started to get involved in environmental policy. The Canada Water Act (1970) and the Clean Air Act (1971) - two facilitating statutes - were essentially building on the need for federal-provincial co-operation in these areas. The federal department for the environment (Environment Canada) was also created in 1971. As in the United States, regulations adopted by the provinces relied mostly on standards based on best available technology.

6. Environmental policy activity slowed substantially from the mid-1970s to the mid-1980s, when Canada had to face two energy crises, rising inflation and unemployment, and a deep recession. It revived in the late 1980s when public concern about environmental issues re-emerged. ${ }^{5}$ Both the federal government and the provinces passed a second round of environmental legislation, with the former taking a high profile on environmental issues in that period. The Canadian Environmental Protection Act (1988), which consolidated several pieces of environmental legislation, significantly strengthened the federal government's role in the control of toxic substances despite considerable resistance from some provinces. Resistance to the Canadian Environmental Assessment Act, originally introduced in 1990 but adopted only in 1995, has been even stronger. The provinces, which have their own environmental assessment legislation, felt that it would threaten their capacity to control economic development within their jurisdiction. In the early 1990s, two judicial decisions regarding large resource infrastructure projects brought to the Federal Court by environmental NGOs, had required the federal government to conduct environmental assessments. The new legislation provides the federal authorities with more discretion to

4. At the end of the 19th century, the federal government made some attempts to take control of provincial resources and the associated revenues, but it lost the constitutional battle (Hessing and Howlett, 1997).

5. For an analysis of the relative salience of environmental and economic concern in public opinion, see Harrison (1996). 
decide on the necessity of conducting reviews in some areas, while at the same time strengthening their obligations in others. ${ }^{6}$

7. In 1990, the federal government also launched the Green Plan, a policy framework and action plan for sustainable development, in which it committed itself to substantial additional spending on the environment over the following five years (C\$3 billion compared with annual federal environmental expenditure of about $\mathrm{C} \$ 1.3$ billion, which represented 1.2 per cent of overall budgetary expenditure at the time). The plan put an emphasis on environmental research, national parks and monitoring and education programmes, but also included quantitative targets on specific environmental issues. All provinces also established sustainable development plans in the early 1990s, some with associated special funds.

8. Subsequently, the impetus for strengthening environmental policies weakened at all government levels as a result of the fiscal consolidation effort, and only about 50 per cent of the sums programmed in the Green Plan were finally allocated. Cuts weighed heavily on environmental departments. Environment Canada's budgets stopped increasing in 1994/95 and had decreased by about 30 per cent in nominal terms by 1998/99 (compared to a 6 per cent reduction of overall federal budgetary expenditure). ${ }^{7}$ In the face of these budgetary constraints, the federal government has reduced its transfers to provinces for "shared responsibility" in the environmental area and has signed agreements with the provinces to carry out inspections, collect information and in cases where the provincial regulations had been considered equivalent, give priority of intervention to the provinces. The provinces, on the other hand, have also substantially reduced their environmental budgets: by up to about 60 per cent between 1994/95 and 1998/99 in Ontario, for example, a period when overall provincial expenditure was roughly stable.

9. Generally, the policy approach to environmental issues has been rather "co-operative". The regulatory standards have generally been developed through close co-operation among the federal government, the provincial government and industry, and the authorities have shown flexibility in cases of non-compliance operative (Harrison, 1995). Voluntary agreements have also become the cornerstone of federal policy on pollution control. Hence, in practice, there is a lot of self-regulation. Litigation, on the other hand, has played a relatively small role - in particular when compared with the United States although it gained some importance in the 1990s. The use of economic instruments has been very limited at the various government levels, and, even though the issue has raised interest in the past decade, it is not significantly increasing.

10. Cost considerations have also played a role in shaping resource and environmental policies, in the sense that profit margins, the viability of the industry subject to regulation, employment patterns and international competitiveness issues have been taken into account. Yet, formal cost-benefit analysis has been relatively scarce, although its use would seem to have increased in the 1990s. Environmental legislation generally prescribes the examination of a measure's economic, environmental and social consequences, but cost-benefit analysis as such is not required. Under the more general framework of regulatory policy, a guide to cost-benefit analysis has been elaborated, but it is not prescriptive, and the

6. To avoid regulatory duplication in public consultation processes, it also allows the establishment of joint federal-provincial panel reviews.

7. Environment Canada budget does not account for all federal environmental expenditure; in 1990/91, it accounted for slightly more than half. More recent figures for overall federal environmental expenditure are not available.

8. Federal environmental expenditures are small in relation to those incurred by provincial and local governments (about 20 per cent in 1990/91), but in the poorest provinces federally supported activities are not negligible. 
authorities concerned have discretion to decide over whether such analysis is necessary. ${ }^{9}$ Environment Canada has also developed models to estimate the environmental costs of air pollution, for example, and these models are being diffused to provincial and territorial governments, thereby enhancing their capacity to use cost-benefit analysis.

\section{Administrative framework}

11. Environment departments have been given responsibility for environmental protection at both levels of government, but substantial powers have been left in the hands of other departments, notably the agriculture, energy (and more widely natural resources) and transport departments, but also fisheries and health. As in other OECD countries, this division of responsibilities also reflects the fact that other goals occasionally override environmental objectives. To address co-ordination issues, various mechanisms have been put in place at the federal and provincial levels, as well as between the two levels (co-ordinating committees, interdepartmental research initiatives, interdepartmental networks and information sharing).

12. The shared nature of environmental jurisdiction also requires close co-operation between the different levels of government. The Canadian Council of Ministers of the Environment (CCME), composed of the environment ministers of the ten provinces, the three territories and the federal government, is the main forum through which federal/ provincial co-ordination on environmental matters is negotiated and formalised. Over the last decade, it has developed substantive joint programmes, on contaminated sites and urban smog, for example. Bilateral agreements on specific issues have also been signed between the federal departments concerned and individual provinces (such as one with Quebec on pulp and paper regulation). More recently, in early 1998, all provinces (except Quebec) and the federal government signed a CCME Canada-Wide Accord on Environmental Harmonisation, which aims at clarifying the respective roles and responsibilities for environmental management. ${ }^{10}$ Other federal-provincial-territorial ministerial councils have been established for natural resource issues, such as forests, agriculture, wildlife, and a joint one for energy and the environment.

13. At the federal level, since 1995, there has been a Commissioner of the Environment and Sustainable Development, a rather unique function among OECD countries. The Commissioner is in charge of auditing federal policies for sustainable development, reporting on the extent to which federal departments are implementing the sustainable development strategies they have elaborated since 1997, as well as on specific themes. The role of the yearly reports, which are delivered to the Auditor General and the Parliament, is to criticise things which are found wrong in the policy reviewed. Although they have no direct influence on policies, these reports play an important role in providing and disseminating information, raising public awareness, and providing recommendations for policy reform to the departments concerned. They have also provided valuable input to this paper.

14. Environmental policy formulation relies quite heavily on consultation processes. For example, the National Roundtable on the Environment and the Economy, an independent agency of the federal government composed of leaders from all sectors of society, provides information and tries to clarify the state of the debate on emerging issues with both environmental and economic implications. ${ }^{11}$ To prepare

9. When cost-benefit analysis is conducted, it is not obligatory that the option ranking best be chosen; in the case where benefits do not exceed costs, a supplementary justification is required.

10. One of its main provisions is that specific roles and responsibilities will be attributed to one level of government only. This has important implications in the area of environmental assessment in particular, where provinces are likely to take the lead.

11. Such roundtables also exist at the provincial level. 
Canada's national strategy on climate change, a National Secretariat on Climate Change has also been established.

\section{International context}

15. Policies for natural resources and the environment are also bound by the various international agreements that Canada has signed. The North American Free Trade Agreement (NAFTA) has implications for resource policies, in particular for energy, since it specifies that export and domestic prices have to be equal - ruling out the possibility of implementing an energy export tax as existed in the 1970s and provides rules for handling periods of shortage. By contrast, NAFTA seems to have had little effect on environmental policy-making. Canada also has long-standing experience of co-operation on transboundary environmental issues with the United States, including through a number of bilateral agreements on boundary waterways, such as the Great Lakes, air quality and acid rain, waterfowl management, and some animal species. Canada is also part to the 1994 Oslo Protocol on sulphur dioxide, which set quantitative targets for emissions reduction for the eastern provinces. Finally, Canada has signed, though not yet ratified, the Kyoto Protocol for reducing greenhouse gas emissions.

The federal government is responsible for negotiating these international agreements. However, Canada is one of the few federal countries in the OECD in which an international agreement in force in federal law is not necessarily binding on the provinces. Implementation of international agreements in matters of provincial competence is subject to assent by provinces. Here also, the CCME tries to harmonise procedures and views among the provinces and between the provinces and the federal government, but it works on a consensus basis. Hence, implementing common policies on global or regional issues may be particularly challenging. 


\section{ANNEX II. BACKGROUND MATERIAL ON THE MANAGEMENT OF THE ATLANTIC FISHERY}

\section{Factors underlying the fisheries collapse}

1. Assessment of fisheries conservation standards is difficult, as the biology of stocks is not fully understood and stocks are subject to environmental shocks. The Canadian scientific estimations also suffered from data limitations. Stock assessments were based on data collected from research survey cruises and on commercial fishery landing statistics. Survey data indicated a decline for some species, but not the data on offshore commercial fishing, which reflected fishing with increasingly sophisticated technology in areas of high fish concentrations (Report of the Auditor General of Canada, 1997). As early as 1986 scientists had established that they had been greatly overestimating the size of the stock. Prediction errors were compounded by a decision-making process that allowed substantial flexibility vis-à-vis scientific recommendations (with for instance a rule specifying that the total allowable catch could be set halfway between the current fishing mortality level and the one corresponding to safe conservation standards).

2. To get the highest catch possible as quickly as possible, fishermen borrowed to invest in larger and better equipped vessels, which forced them to catch even more fish to repay their debts. This also made for more forceful resistance to controlling catches, not to say to shrinkage of the sector.

3. A consistent time series for subsidies to Atlantic fisheries is not available. According to Schrank (1996), total public financial outlays doubled over the 1980s, reaching C\$ 1 billion in 1990/91, exceeding the value of the landed catch. Over the decade they amounted to $\mathrm{C} \$ 8$ billion, somewhat less than half being paid in the form of unemployment insurance. The figure seems particularly high, however, compared with that provided in the 1997 Auditor General's report of \$270 million in unemployment insurance payments in 1988-89. In Newfoundland, the provincial government subsidised up to 35 per cent of the capital costs of vessel purchases (Munro and McCorquodale, 1981).

4. The centralised and top-down character of fisheries management in the 1970s and 1980s, whereby government regulations covered virtually every aspect of the harvesting operation, also played a significant part in the Atlantic fishery collapse (Charles, 1994).

\section{Evaluation of the TAGS labour adjustment measures}

5. Labour adjustment measures (as well as the other non-income support measures) were abandoned in 1996 when the sum available for income support turned out to be insufficient for the number of eligible individuals. Some of the key findings of the evaluation conducted in 1998 follow: *

- In 1996, 27 per cent of the TAGS clients had earned income from sources other than TAGS that was at least 80 per cent of their pre-closure earnings. In addition, 4 per cent had accepted early retirement or license retirement packages.

* $\quad$ For more details, see http://www11.hrdc-drhc.gc.ca/edd/TAG_brf.shtml. 
- However, of these so-called "adjusted" TAGS clients, 75 per cent were still relying on employment insurance or TAGS income support for up to 80 per cent of their income.

- In addition, 80 per cent of the TAGS clients who worked in 1996 still did so in the fishing or fish-processing sector.

\section{The Canadian Fisheries Adjustment and Restructuring programme (CFAR)}

This programme concerns both Atlantic and Pacific Fisheries.

6. Final cash payment is proposed to those enrolled in TAGS who did not opt for license retirement or early retirement, equal to the maximum amount they would have received if TAGS had continued to its original termination date of 15 May, 1999.

7. Adjustment measures include: related income support to assist individuals to become selfemployed and to gain practical work experience and training to develop new skills; mobility assistance to help people willing to move to find new employment opportunities; changes to employment insurance (EI) regulations whereby weeks of paid TAGS income support count as labour force attachment in order to make it easier to requalify for EI.

\section{Table A1. The CFAR: sums programmed and spent}

\begin{tabular}{lrc}
\hline C\$ millions & Sums programmed & Sums spent as of March 2000 \\
\hline Licence retirement & 250 & 162 \\
Early retirement & 65 & 79 \\
Final cash payments & 180 & 202 \\
Adjusted measures & 135 & 108 \\
Economic development measures & 100 & 3 \\
Total & 730 & 454 \\
\hline
\end{tabular}

\section{The Oceans Management Strategy}

8. In Canada, there are more than 20 federal government departments and agencies with some degree of responsibility for activities in, or affecting, the oceans. In 1997, Parliament passed the Ocean Act. This legislation sets out an approach for oceans management, based on a sustainable development approach, integrated management and the precautionary approach, which calls for co-operation and collaboration in this sector, under the leadership of the Minister of Fisheries and Oceans. One of the key parts of the Act is the development and implementation of a national Oceans Management Strategy.

9. The Ocean Management Strategy will focus on three main objectives: balancing economic, environmental and social goals; managing the increasing complexity and diversity of ocean use; and engaging communities and stakeholder in making decisions that affect them. Ecosystems are under stress due to rising and often competing demands among resource users (commercial fishing, transportation, oil and gas, telecom, recreation and tourism, etc.). The challenge therefore is to strike a balance between competing resource users and the need to conserve the resource. To this end, policy has to shift from a primarily fishery focus to a multi-use focus. In particular, the interface between land and water (for example, the impact of land-based pollution such as urban run-off, agricultural drainage and sewage discharges on fishing stocks) has to be taken into account. This involves dealing with a number of different players and using new and multiple regulatory instruments. 
10. The implementation of the Oceans Act, and in particular the Ocean Management Strategy, is underway. Up to now, the main implementation activities have included initiating work on Marine Protected Area, Integrated Management projects and Marine Environmental Quality. An integral part of the development process for these initiatives is discussions with fishing groups and other oceans space interests. The scope of integrated management is very broad, taking into account all existing and potential coastal and marine activities, and presents challenges to institutions, organisations and individuals used to dealing bilaterally with their interest. Given the nature of the management challenge, raising public awareness and understanding is another key-element of the strategy. 


\section{ECONOMICS DEPARTMENT \\ WORKING PAPERS}

289. Encouraging Environmentally Sustainable Growth in Sweden (March 2001) Deborah Roseveare

288. Public Spending in Mexico: How to Enhance its Effectiveness (March 2001) Bénédicte Larre and Marcos Bonturi

287. Regulation in Services : OECD Patterns and Economic Implications (February 2001) Giuseppe Nicoletti

286. A Small Global Forecasting Model

(February 2001) David Rae and David Turner

285. Managing Public Expenditure : Some Emerging Policy Issues and a Framework for Analysis (February 2001) Paul Atkinson and Paul van den Noord

284. Trends in Immigration and Economic Consequences

(February 2001) Jonathan Coppel, Jean-Christophe Dumont and Ignazio Visco

283. Economic Growth: The Role of Policies and Institutions.

Panel Data Evidence from OECD Countries

(January 2001) Andrea Bassanini, Stefano Scarpetta and Philip Hemmings

282. Does Human Capital Matter for Growth in OECD Countries? Evidence from Pooled Mean-Group Estimates (January 2001) Andrea Bassanini and Stefano Scarpetta

281. The Tax System in New Zealand: An Appraisal and Options for Change (January 2001) Thomas Dalsgaard

280. Contributions of Financial Systems to Growth in OECD Countries (January 2001) Michael Leahy, Sebastian Schich, Gert Wehinger, Florian Pelgrin and Thorsteinn Thorgeirsson

279. House Prices and Economic Activity

(January 2001) Nathalie Girouard and Sveinbjörn Blöndal

278. Encouraging Environmentally Sustainable Growth in the United States (January 2001) Paul O’Brien

277. Encouraging Environmentally Sustainable Growth in Denmark (January 2001) Paul O’Brien and Jens Høj

276. Making Growth more Environmentally Sustainable in Germany (January 2001) Grant Kirkpatrick, Gernot Klepper and Robert Price

275. Central Control of Regional Budgets : Theory with Applications to Russia (January 2001) John M. Litwack

274. A Post-Mortem on Economic Outlook Projections (December 2000) Vassiliki Koutsogeorgopoulou 


\section{ECO/WKP(2001)16}

273. Fixed Cost, Imperfect Competition and Bias in Technology Measurement: Japan and the United States (December 2000) Kiyohiko G. Nishimura and Masato Shirai

272. Entry, Exit, and Aggregate Productivity Growth: Micro Evidence on Korean Manufacturing (December 2000) Chin-Hee Hahn

271. The Tax System in Korea: More Fairness and Less Complexity Required (December 2000) Thomas Dalsgaard

270. A Multi-Gas Assessment of the Kyoto Protocol (October 2000) Jean-Marc Burniaux

269. The Changing Health System in France (October 2000) Yukata Imai, Stéphane Jacobzone and Patrick Lenain

268. Inward Investment and Technical Progress in the UK Manufacturing Sector (October 2000) Florence Hubert and Nigel Pain

267. Aggregate Growth: What have we Learned from Microeconomic Evidence? (October 2000) John Haltiwanger

266. Determinants of Long-term Growth: A Bayesian Averaging of Classical Estimates (BACE) Approach (October 2000) Gernot Doppelhofer, Ronald I. Miller and Xavier Sala-i-Martin

265. The Great Reversals: The Politics of Financial Development in the $20^{\text {th }}$ Century (October 2000) Raghuram G. Rajan and Luigi Zingales

264. Trade and Growth: Still Disagreement about the Relationship (October 2000) Robert Baldwin

263. Growth Effects of Education and Social Capital in the OECD Countries (October) Jonathan Temple

262. Human Capital in Growth Regressions: How Much Difference Does Data Quality Make? (October 2000) Angel de la Fuente and Rafael Doménech

261. Raising the Speed Limit: US Economic Growth in the Information Age (October 2000) Dale W. Jorgenson and Kevin J. Stiroh

260. Summary of an Informal Workshop on the Causes of Economic Growth (October 2000) Jonathan Temple

259. Knowledge, Technology and Economic Growth: Recent Evidence from OECD Countries (October 2000) Andrea Bassanini, Stefano Scarpetta and Ignazio Visco

258. Average Effective Tax Rates on Capital, Labour and Consumption (October 2000) David Carey and Harry Tchilinguirian

257. The Health Care System in Poland (September 2000) Nathalie Girouard and Yutaka Imai

256. Public Expenditure Reform: The Health Care Sector in the United Kingdom (August 2000) Vincent Koen 